\title{
DEVELOPMENT AND CHARACTERIZATION OF A CHAMBER GRAM ESTIMATOR
}

\author{
.by \\ G. B. Dulco \\ V. P. Gupta \\ D. K. Balmer
}

July 1995

ROCKY FLATS ENVIRONMENTAL TECHNOLOGY SITE

P. 0. BOX 464

GOLDEN, CO 80402-0464

PREPARED UNDER CONTRACT DE-AC04-90DE62349

FOR THE

U.S. DEPARTMENT OF ENERGY

DISTAIBUTION OF THIS DOCUMENT IS UNLIMITED 


\section{DISCLAIMER}

This report was prepared as an account of work sponsored by an agency of the United States Government. Neither the United States Government nor any agency thereof, nor any of their employees, makes any warranty, expressed or implied, or assumes any legal liability or responsibility for the accuracy, completeness, or usefulness of any information, apparatus, product, or process disclosed, or represents that its use would not infringe privately owned rights. Reference herein to any specific commercial product, process, or service by trade name, trademark, manufacturer, or otherwise, does not necessarily constitute or imply its endorsement, recommendation, or favoring by the United States Government or any agency thereof. The view and opinions of authors expressed herein do not necessarily state or reflect those of the United States Government or any agency thereof.

This report has been reproduced directly from the best available copy.

Available to DOE and DOE contractors from the Office of Scientific and Technical Information, P. O. Box 62, Oak Ridge, TN 37831; prices available from (615) 576-8401, FTS 626-8401.

Available to the public from the National Technical Information Service, U.S. Department of Commerce, 5285 Port Royal Rd., Springfield, VA 22161. 


\section{DISCLAIMER}

Portions of this document may be illegible in electronic image products. Images are produced from the best available original document. 


\section{DEVELOPMENT AND CHARACTERIZATION OF A CHAMBER GRAM ESTIMATOR}

by

G. B. Dulco

V. P. Gupta

D. K. Balmer
JUL 2 \& 1935

OSTI

Published July 1995

Kwic Index

Gram Estimator

Iine Generated waste Nondestructive Assay Plastic Scintillator

ROCRY FLATS ENVIRONMENTAL TECHNOLOGY SITE TECHNOLOGY DEVELOPMENT

P. O. BOX 464

GOLDEN, CO 80402-0464 


\section{TECHNICAL REVIEWS}

This report has been reviewed for content by a qualified subject matter expert (SME) and the conclusions and recommendations have been read and understood by the undersigned.

PRINCIPAL INVESTIGATOR: $\frac{\text { V. P. Gupta }}{\text { Tech. Investigations }}$

PREPARED BY: G. B. Dulco, V. P. Gupta and D. K. Balmer Print Names

REVIEWED BY: J. G. Fleissner Print Name, SME
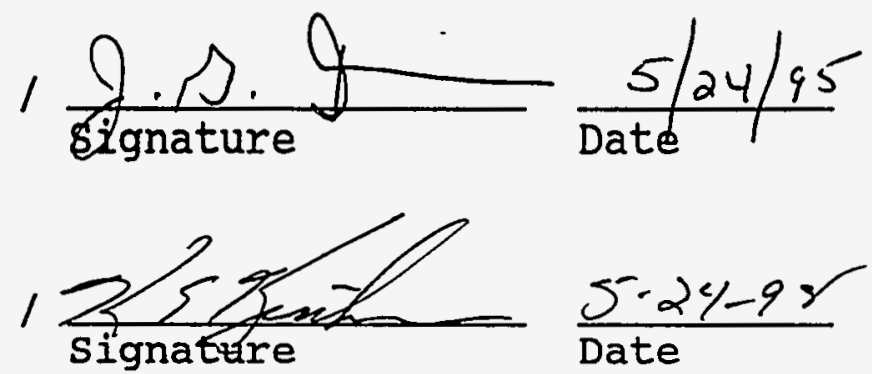

$\frac{5-24-95}{\text { Date }}$
APPROVED BY: K. E. Kirchner Print Name, Manager Tech. Investigations 


\section{ABSTRACT}

The Chamber Gram Estimator (CGE), Model SAM-1B is a small article gamma monitor originally designed to screen items for radioactive contamination that may be placed into its chamber. Four plastic scintillator detectors detect photons emitted from bulk quantities of fissile materials in line generated waste and provide a fissile mass content estimate of waste packages. With the present CGE, a few grams of ${ }^{239} \mathrm{Pu}$ could be distinguished above background in light matrix samples. It is controlled by a personal computer that uses a menu driven operating program. The program is designed to reduce the potential for operator error while obtaining a fissile material gram estimate of a line generated waste package prior to placement in a drum.

This report describes the work performed to characterize the counting chamber for fissile material estimation. The operating features of the CGE, the results and conclusions drawn from the experiments, and the future work recommended for the next generation CGEs are also described.

The CGE provides advantages over hand-held Ludlum 12-12 survey-type instruments presently in use. The CGE is easy to operate, does not require manual manipulation to measure the total surface of the sample, and provides a display free of rate meter response-time effects or the need for visual averaging. Moreover, the response variations due to sample geometry are significantly less than with a hand-held arrangement, particularly, for the low density matrix samples appropriate for estimation. The waste packages are placed inside the instrument's shielded chamber which effectively eliminates gamma exposure to operators from waste packages. 


\section{ACKNOWLEDGEMENTS}

Many groups and staff members at Rocky flats Environmental

Technology site helped during this work, and the authors gratefully acknowledge their help.

Moreover, the authors would like to thank the management of EG\&G

Rocky Flats, DOE RFFO-RF, and DOE HQ for providing technical

development funding for this project. 


\section{TABLE OF CONTENTS}

Technical Review............................ ii

Abstract................................

Acknowledgements.............................. vi

Table of Contents.............................. v

1. INTRODUCTION............................. I

2. DESCRIPTION OF CHAMBER GRAM ESTIMATOR.............. 2

3. THEORETICAL CONSIDERATIONS..................... 4

4. EXPERIMENTS PERFORMED ON THE CGE.................. 4

4.1 Preliminary Electronics and Internal Shield settings... 4

4.2 Calibration of the CGE...................... 5

4.3 CGE Source Position Characterization study.......... 23

4.4 Other Characterization Studies Performed on CGE....... 39

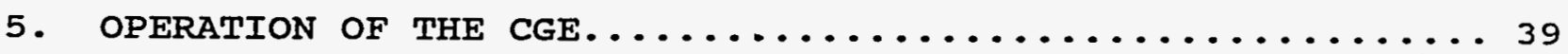

6. RESULTS AND DISCUSSIONS......................4 41

7. CONCLUSIONS AND RECOMMENDATIONS....................42

8. FUTURE WORK...............................42

9. REFERENCE................................ 43

Appendix A - Photographs of the CGE Setup...............44

A-1. Chamber Gram Estimator setup............ 45

A-2. Inside of Empty CGE.................. 46

A-3. Bagcut Positioned Inside CGE............ 47

Appendix B - Fixed counts and Fixed Real-Time Pulse Height Spectra............................48

B-1(a-e) . Preset Count Pulse Height Spectra...... 49 B-2(a-e) . Fixed Real-Time Pulse Height Spectra.... 54 


\section{DEVELOPMENT AND CHARACTERIZATION OF A CHAMBER GRAM ESTIMATOR}

\section{INTRODUCTION}

The amount of fissile material in low level line generated waste packages can be estimated with gamma radiation measuring instrumentation that measures gamma rays coming out from the surface of such packages. A Iudlum 12-12 Portable Gram Estimator (PGE) is currently used to estimate plutonium (Pu) mass in such packages which have no defined shape. The PGE is calibrated using a 5 gram tank surveillance standard that has the shape of a disk within a 5 inch diameter plate. A study, "Investigation of Portable Gram Estimators" (January 1992, unpublished), pointed out that the PGE is not conservative when estimating packages containing fissile material in a dense material category or Item Description Code (IDC). The study also indicated that for packages with light matrix IDCs, the estimations of plutonium could be in error by as much as a factor of 3 due to geometry effects alone. The PGE is essentially a rate meter coupled to a sodium Iodide (NaI) detector. Due to the limited discrimination capabilities of the rate-meter electronics, a $1 / 16$ inch thick cadmium shield is required for the NaI detector to limit the response from americium $\left({ }^{241} \mathrm{Am}\right)$ which is present in weapons grade plutonium. It cannot compensate for the waste package matrix absorption or for the errors associated with the geometry of the package. Due to a single adjustment for the PGE rate meter, the instrument display cannot provide direct readings specific for different IDCs, and conversion factors must be applied to the results. Moreover, the risk of exposure to the operator is increased due to the need to hold and rotate the package in front of the operator while obtaining the estimate using the PGE.

Developmental work on the Chamber Gram Estimator (CGE) was initiated as a long term solution to the problems associated with the Iudlum 12-12 Portable Gram Estimator ${ }^{1}$. In comparison to the cost of using a segmented can counter, which corrects for density variations in a package, the CGE is an inexpensive and quick method to use in estimating low level line generated waste packages prior to placing them into waste drums. Fissile material estimators must be appropriately characterized for the various waste matrices to avoid violating established criticality safety limits. 
This report describes construction of the CGE and the experiments performed to properly set the electronics and to select the internal chamber shield thickness. Calibration of the instrument using different standards and the source position dependence within the chamber were studied. The operation of the CGE, results and conclusions drawn from the experiments, and the future work recommended for the next generation CGEs are also described.

After performing initial electronic adjustments and mapping the chamber using radioactive sources in Building 881 , the CGE was shipped to Building 771, Room 114 .

\section{DESCRIPTION OF CHAMBER GRAM ESTIMATOR}

The Chamber Gram Estimator, Model SAM-1B is a prototype small article monitor built by TSA Systems, Iongmont, Colorado. It was originally designed to screen items for radioactive contamination that may be placed into its chamber.

The CGE resembles a small refrigerator and has a sample chamber box measuring 15"H $\times 15^{\prime \prime} \mathrm{W} \times 18$ "D (see Photograph in Appendix A). The outside dimensions of the box are $29^{\prime \prime} \mathrm{H} \times 26^{\prime \prime} \mathrm{W} \times 26^{\prime \prime} \mathrm{D}$, and it weighs about 900 pounds. It has 3/8" thick lead shielding on all six sides of the sample chamber. There are four plastic scintillation detectors measuring 10"W $\times 15^{\prime \prime} \mathrm{L} \times 1.5^{\prime \prime}$ thick positioned at the top, bottom, left and right sides of the chamber. The detectors are coupled to four photomultiplier tubes via light pipes. There is a common high voltage bias supply for all four detectors. Figure 1 illustrates a simplified diagram of how counts from two channels are sent to the counter. signals are conditioned by four individual amplifiers that may be adjusted separately. The amplifier signals are discriminated using two separate single channel analyzers (SCA) each combining the response of two detectors. The two SCAs have common threshold and window controls. There are two counting channels, one for each SCA and its associated detector pair.

The CGE was designed to automatically perform a self-test and acquire a new background count rate each time it is powered up. Initial operation involved the use of a hand held terminal. This protocol has been changed through the use of an adjacent personal computer and a menu driven operating program. The program was designed to significantly reduce the potential for operator error while obtaining a $\mathrm{Pu}$ gram estimate of a waste package. An internal shield, 1/8'' thick copper sheet, has been installed inside the CGE chamber to minimize ${ }^{241}$ Am response. 


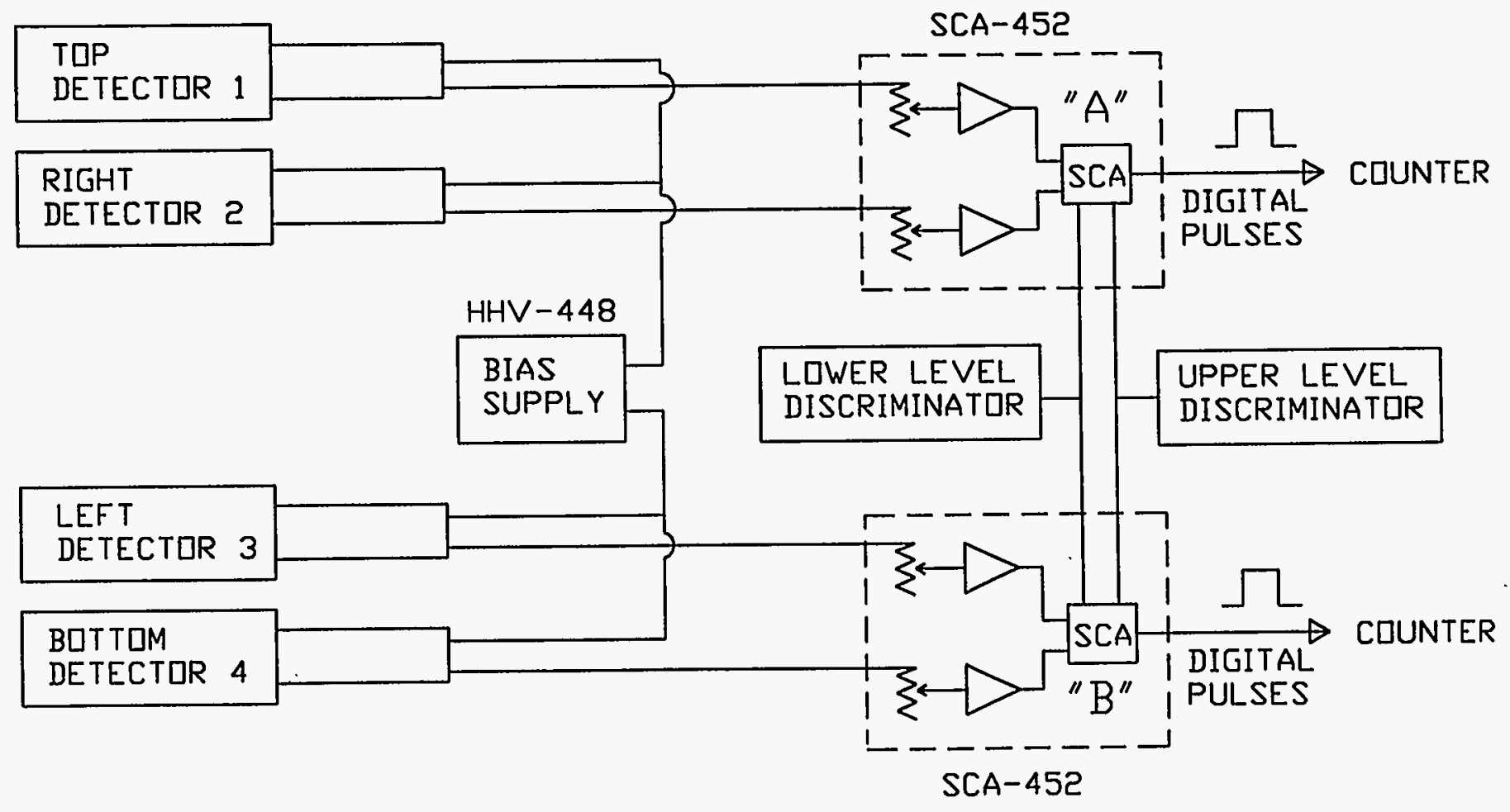

FIGURE 1: Block Diagram - CGE Electronics 


\section{THEORETICAL CONSIDERATIONS FOR THE CGE}

Passive techniques used to estimate $\mathrm{Pu}$ mass in small packages from the gamma-ray flux emitted, is a function of the flux emitted and the fraction of gamma rays detected. The flux emitted depends on (1) the $\mathrm{Pu}$ content of the package, (2) self-absorption in the $\mathrm{Pu}$, i.e., the density and dispersion of the $\mathrm{Pu}$ within the waste package matrix, (3) gamma-ray absorption in the waste material matrix in the package, (4) other gamma ray emitting radioisotopes, such as ${ }^{241} \mathrm{Am}$, in the waste package, and (5) background radiation. Detection of the gamma ray flux is a function of the detector geometry, detector efficiency, energy spectral response, the internal shield to limit the response to low energy photons (due to ${ }^{241} \mathrm{Am}$ ), the external shield to limit the background contribution, and dead time of the detector.

Variables associated with the gamma flux emitted were investigated using several sample configurations. The response of the instrument was measured as a function of fissile material mass using small cylindrical standards containing $\mathrm{PuO}_{2}$. The measurements provided a conservative indication of Iinearity, combining the effects of self-absorption, and to a degree, dead time of the instrument. Variables associated with the photon flux detected were investigated using pulse height analysis and relative efficiency measurements.

\section{EXPERIMENTS PERFORMED ON THE CGE}

\subsection{PRELIMINARY ELECTRONIC AND INTERNAL SHIELD SETTINGS}

Measurements were performed to study the independent response of all four detectors, and these measurements were used to verify optimum operating parameters (e.g., high voltage, amplifier gains, discriminator settings, region-of-interest).

Pulse height spectra for a preset 400,000 integrated counts for two 5 and $50 \mathrm{milligram}{ }^{241} \mathrm{Am}$ standards, two 5 and 50 gram standards containing $\mathrm{PuO}_{2}$, and the background were obtained. These spectra are given in Appendix $B$ and were used to compare electronic efficiencies in determining the optimum region-of-interest (ROI) in combination with amplifier gains and discriminator settings. The data showed a very limited dependence of electronics alignment (ROI) on efficiency for the ${ }^{239} \mathrm{Pu}$ and interferences from the ${ }^{241} \mathrm{Am}$ and background. 
Pulse height spectra for a 180 seconds fixed real-time were obtained for the background and four ${ }^{241} \mathrm{Am}$ and $\mathrm{PuO}_{2}$ standards ( 5 and 50 gram each) and are also given in Appendix B. The data provided a relative count rate comparisons between sample quantities $\left({ }^{239} \mathrm{Pu}\right)$ and interference from the background and ${ }^{241} \mathrm{Am}$. Measurements at different discriminator settings showed that the factory setting was the optimum setting to minimize the response due to ${ }^{241} \mathrm{Am}$.

The data demonstrated adequacy of shields, both external and internal, to allow a few grams of ${ }^{239} \mathrm{Pu}$ to be distinguished above background in light matrix materials and to limit response contribution from ${ }^{241} \mathrm{Am}$ at concentrations of 1,000 parts per million (ppm), respectively, in the chosen operating region.

\subsection{CALIBRATION OF THE CGE}

\subsubsection{Using Triple Encapsulated Standard Sources}

The instrument responses were measured as a function of plutonium mass using small cylindrical standards containing $\mathrm{PuO}_{2}$ compressed within a relatively small volume. These triple encapsulated $\mathrm{PuO}_{2}$ standards (TES) ranged from 5-50 grams of $\mathrm{PuO}_{2}$ (total encapsulation aluminum tube thickness of $\left.3 / 16^{\prime \prime}\right)$. These TESs were placed and counted for 100 seconds inside a tube (1/16" thick aluminum) fitted at the central axis of the clamshells (Figure 2). Calculations indicated that, for proton energies from $60 \mathrm{keV}$ to $150 \mathrm{keV}$, a transmission of only about 65 to 80 percent takes places due to absorption by the aluminum tubes. Self-absorption by the $\mathrm{PuO}_{2}$ source material in the TESs was not calculated, however, it was higher for sources with a larger amount of source material.

These clamshells were filled with different IDC matrix materials which corresponded to expected waste characteristics and did not contain $\mathrm{PuO}_{2}$ within the matrix. For the TES sources, counts were performed for 100 seconds each and net count rates were obtained, after subtracting the background count rate (about $4200 \mathrm{cps}$ ). Calibration data were plotted as shown in Figures 3 through 15.

\subsubsection{Using Clamshell Homogeneous Standard Sources}

Six clamshell homogeneous standards (CHS) were fabricated for IDCs $331,336,337,339,431$, and 480 with approximately 50 grams of $\mathrm{PuO}_{2}$ distributed homogeneously throughout each clamshell matrix. Details of these standards are given in Table 1 . Measurements 


\section{FIGURE 2 \\ CLAMSHELL MAPPING POSITIONS}

REAR OF CHAMBER

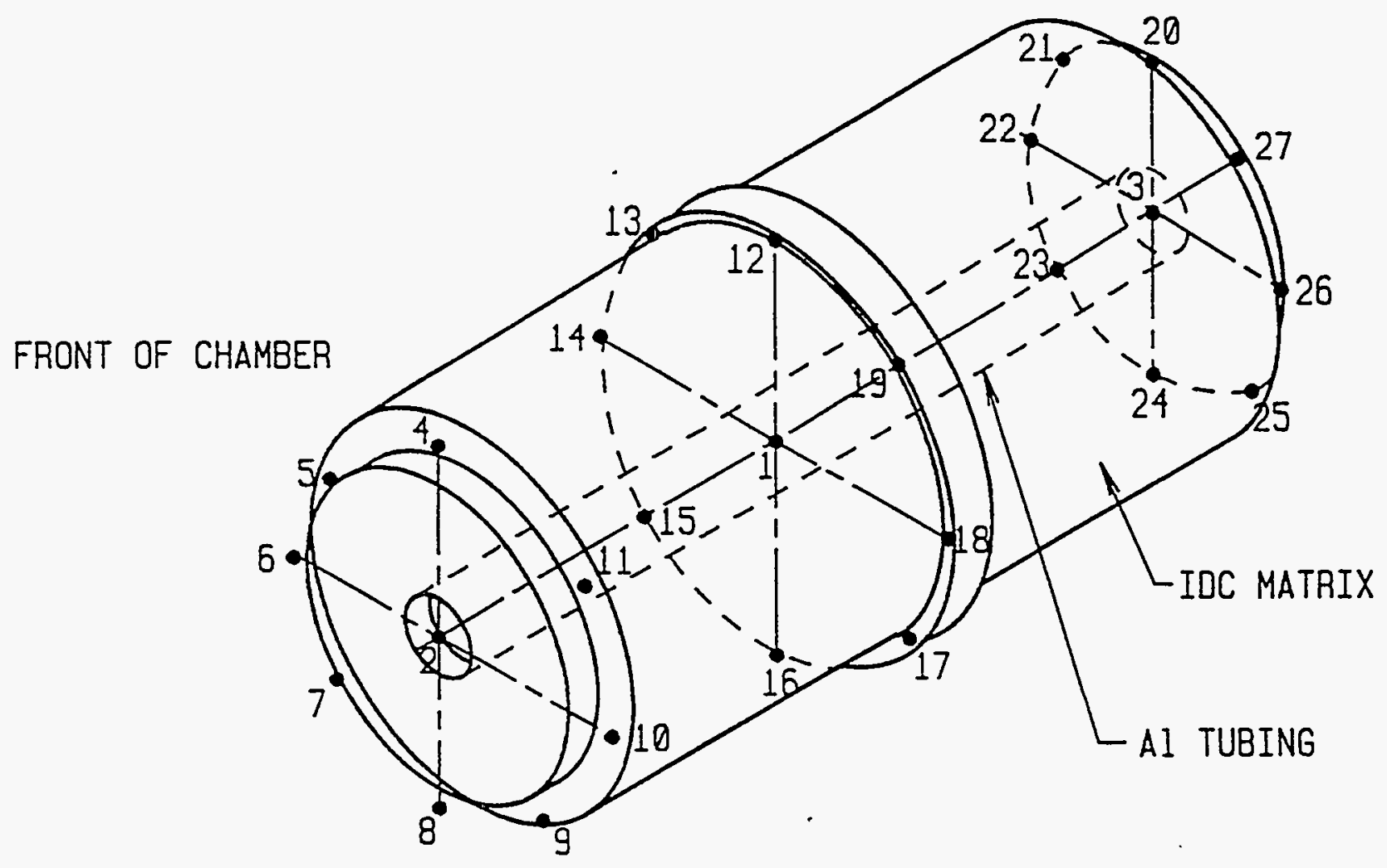




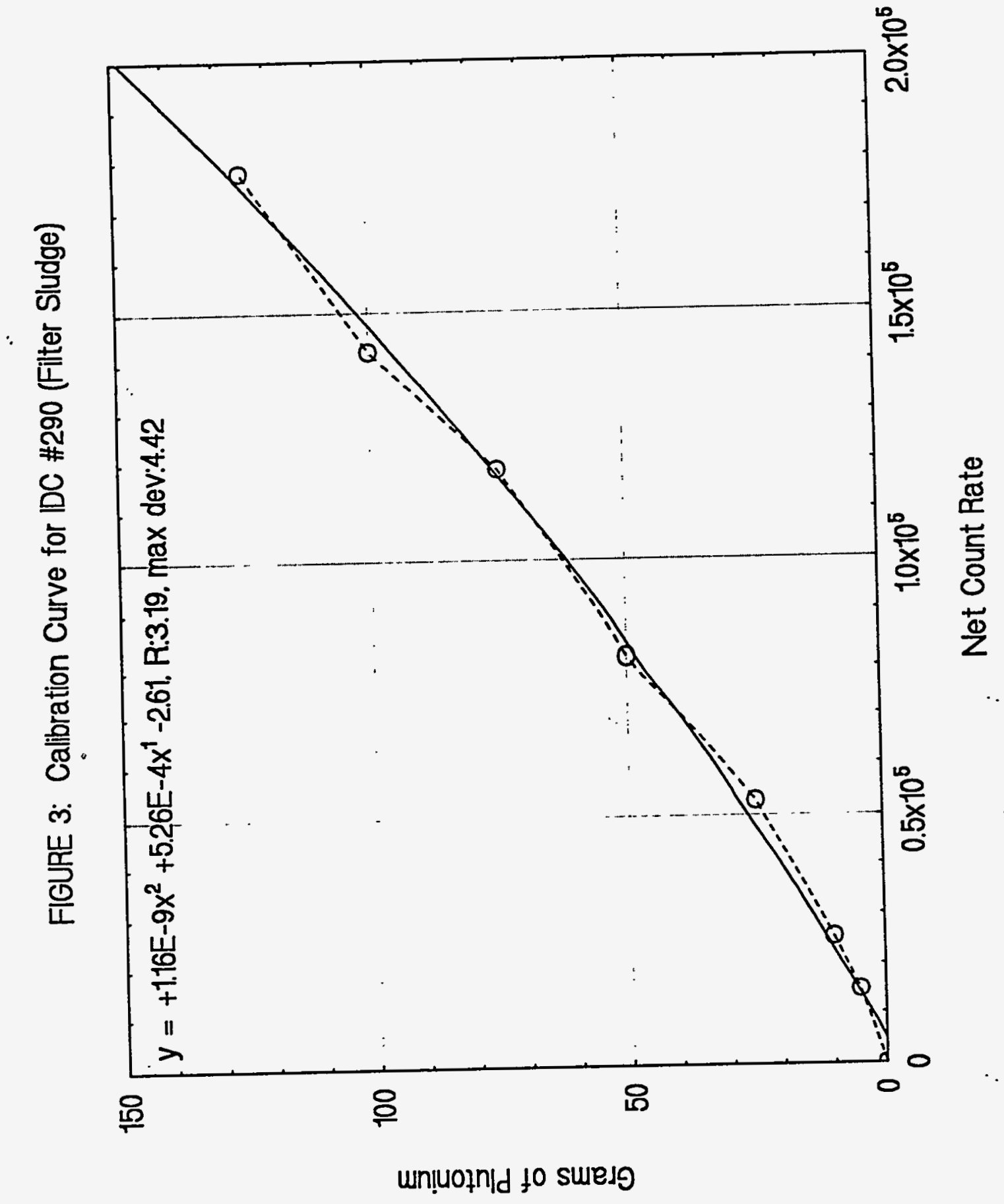




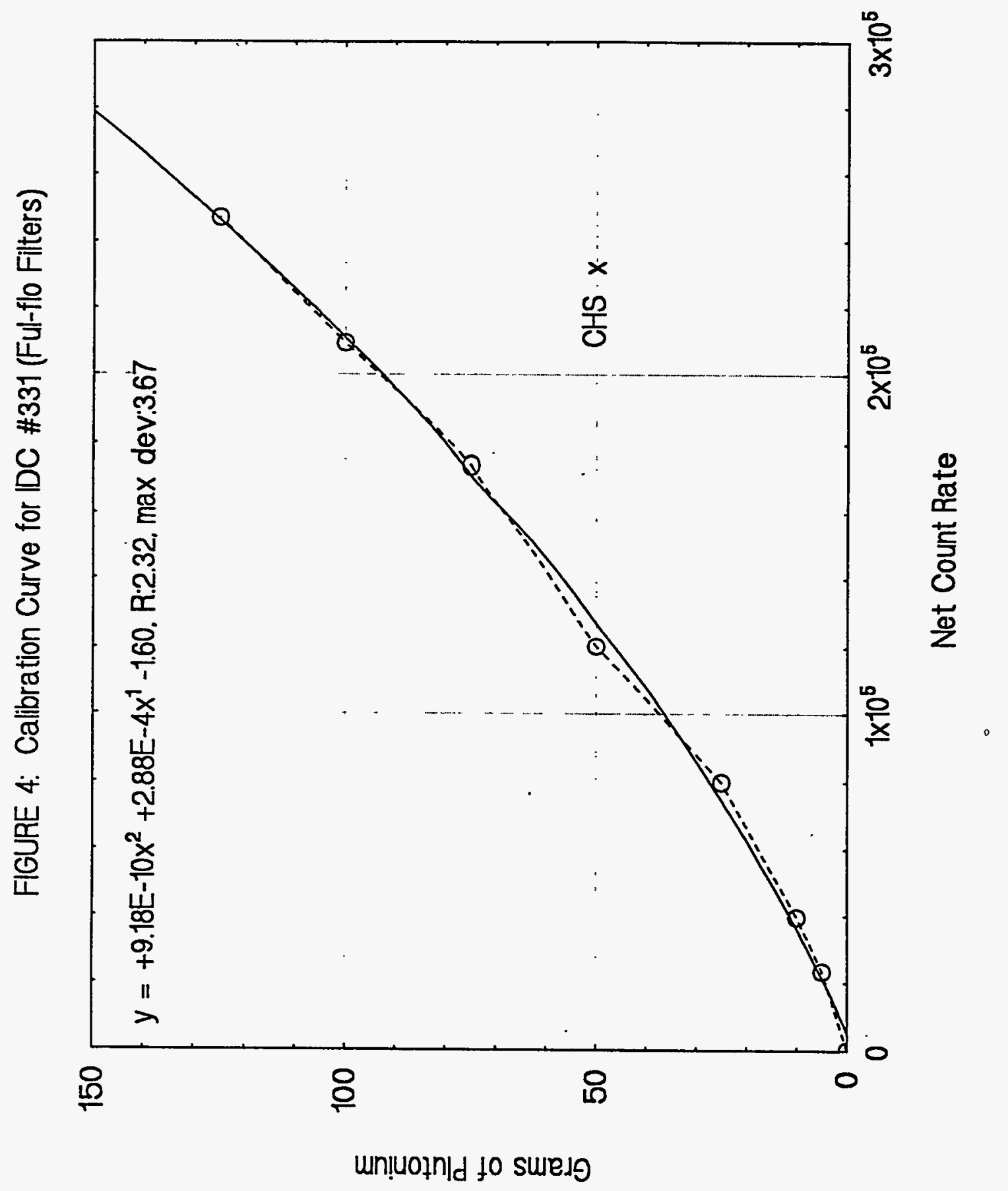


FIGURE 5: Calibration Curve for IDC \#332 (Oily Sludge)

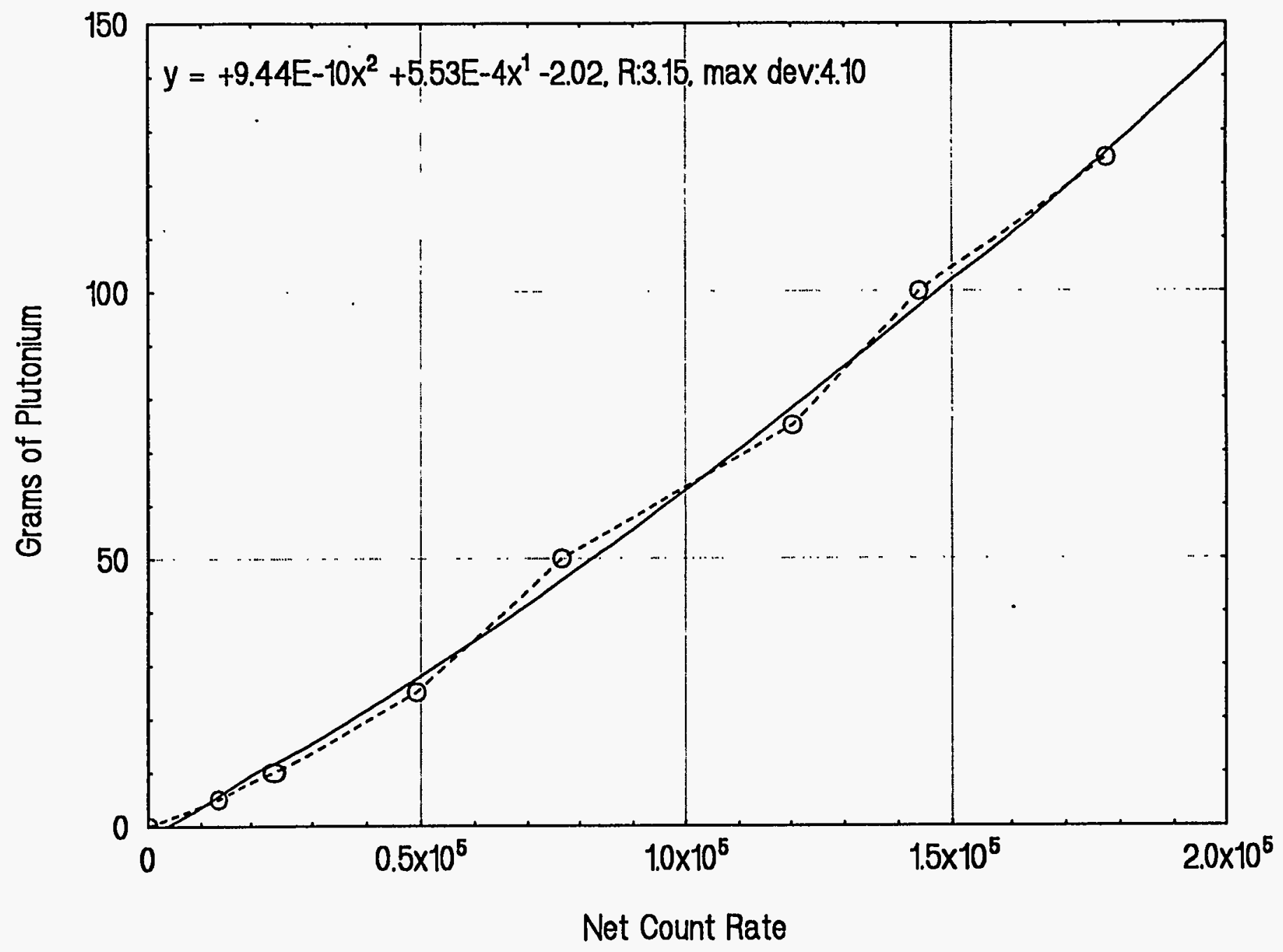


FIGURE 6: Calibration Curve for IDC \#336 (Wet Combustibles)

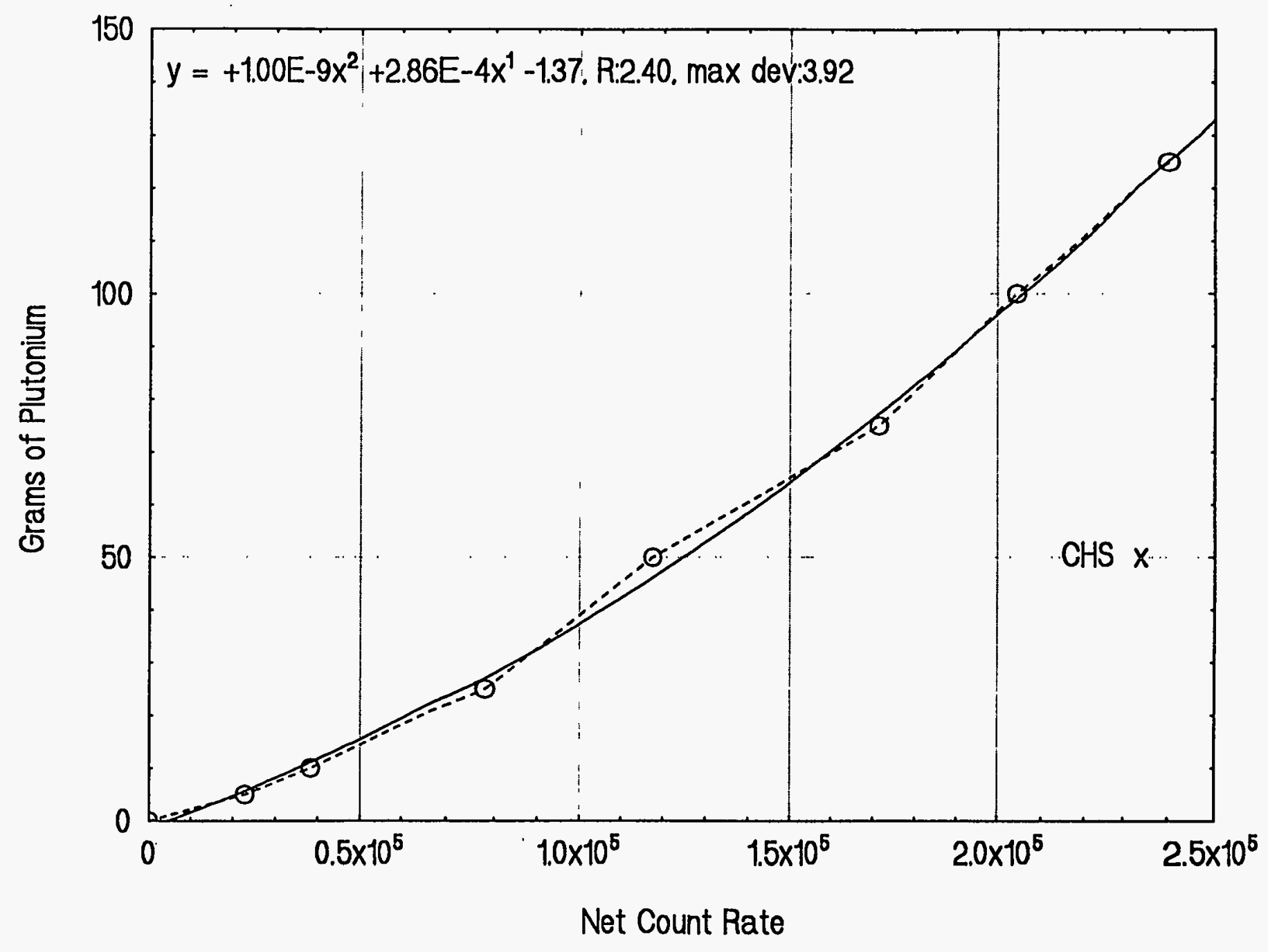




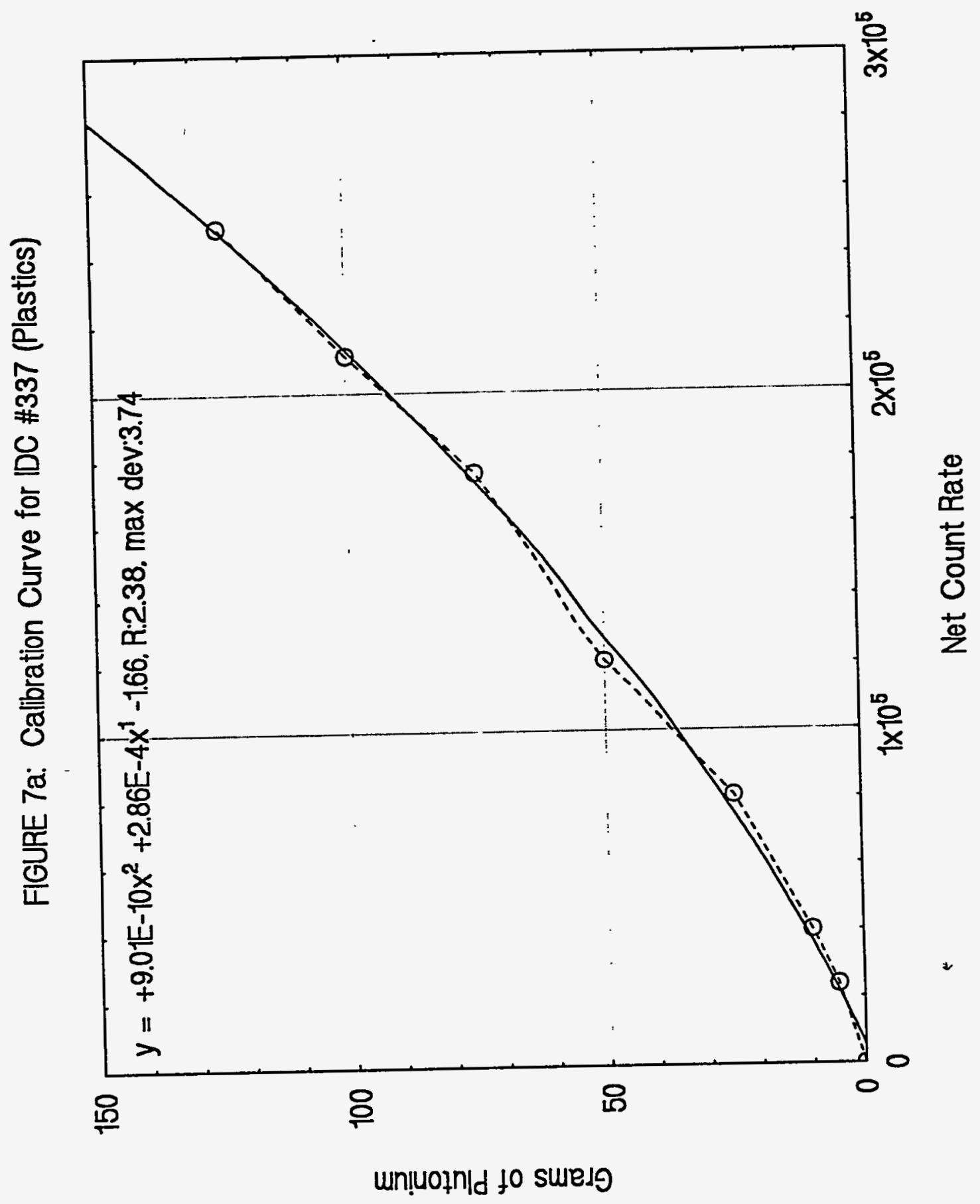




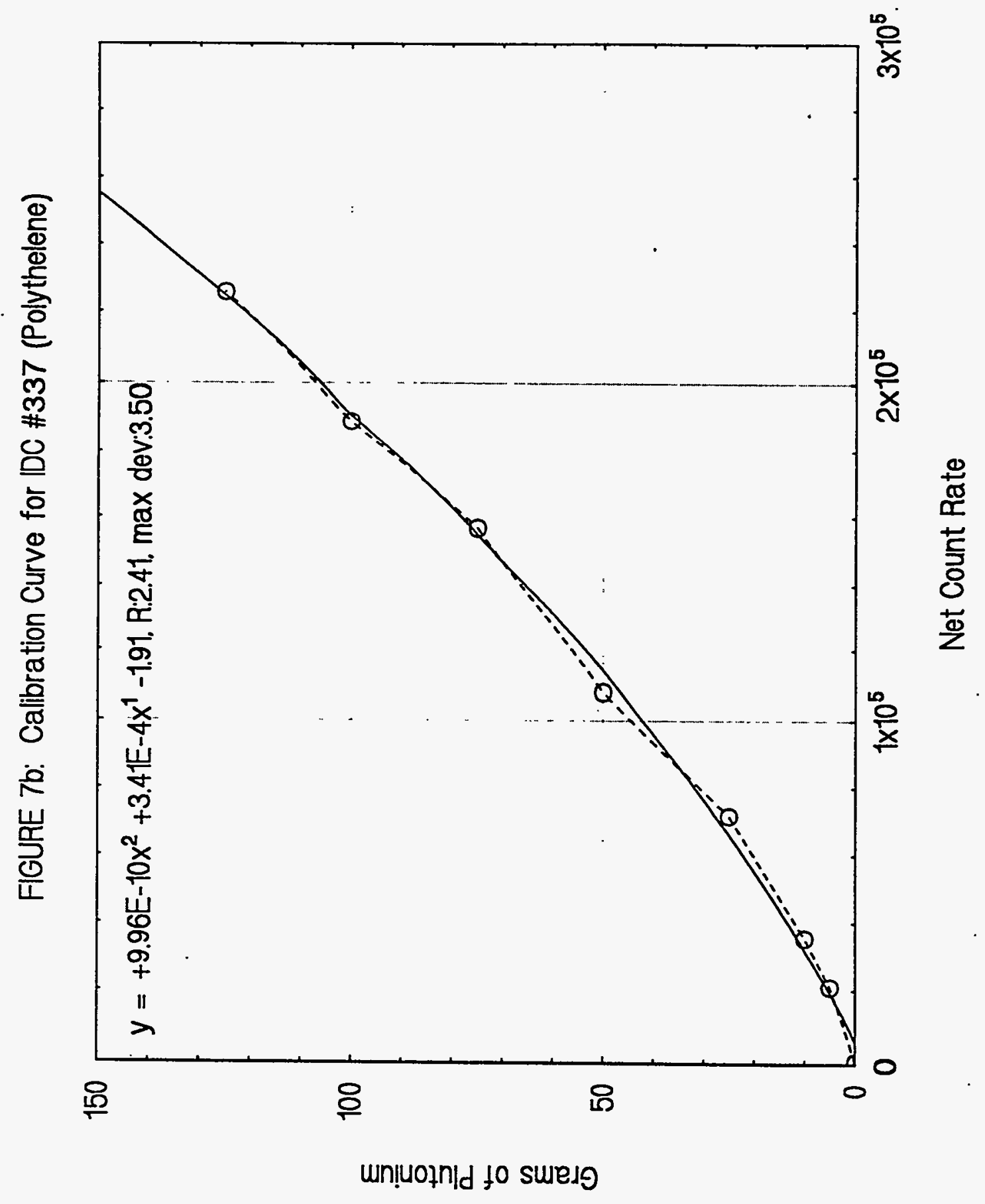


FIGURE 7c: Calibration Curve for IDC \#337 (Teflon + PVC)

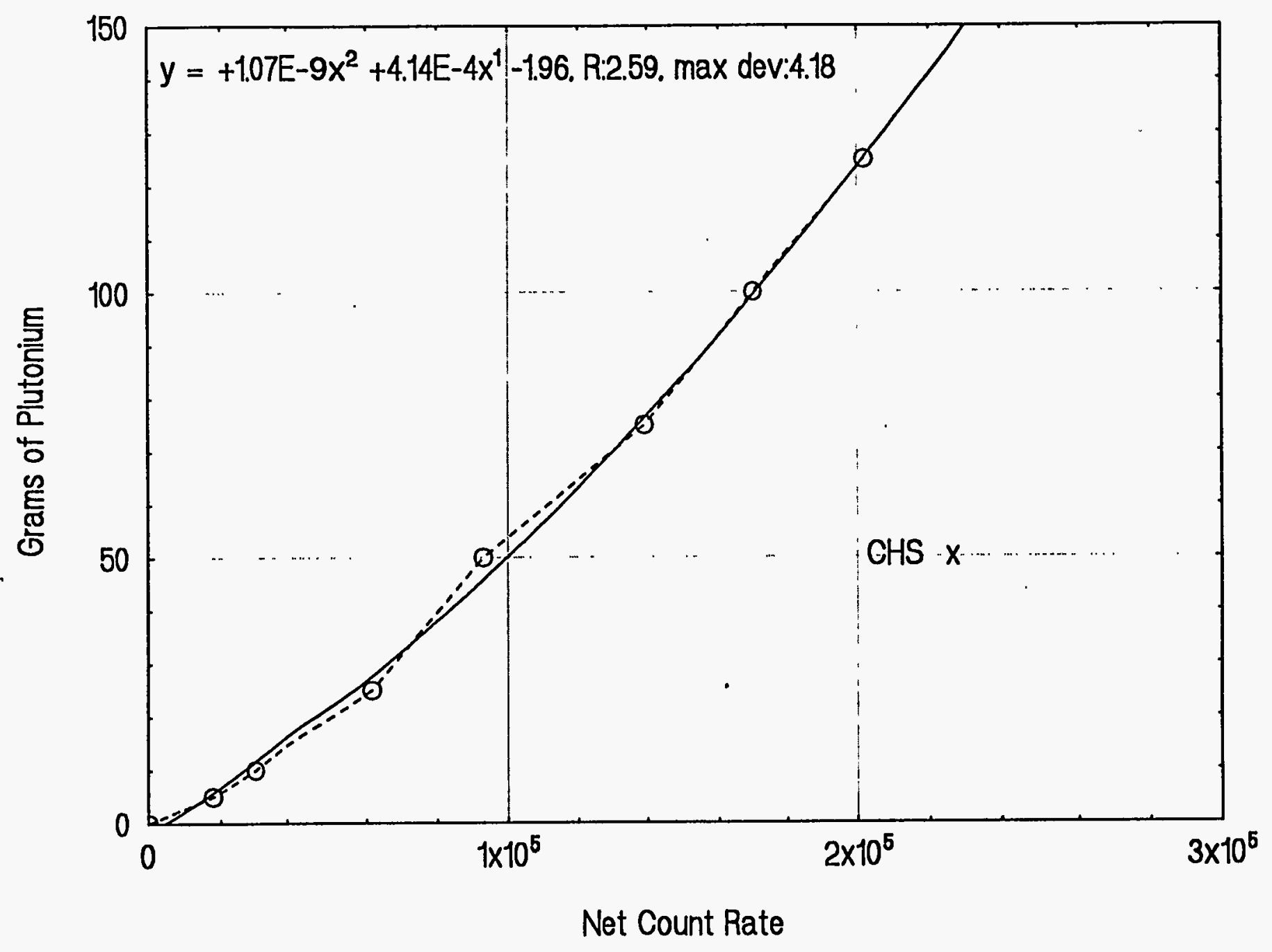


FIGURE 8: Calibration Curve for IDC \#338 (Filter Media)

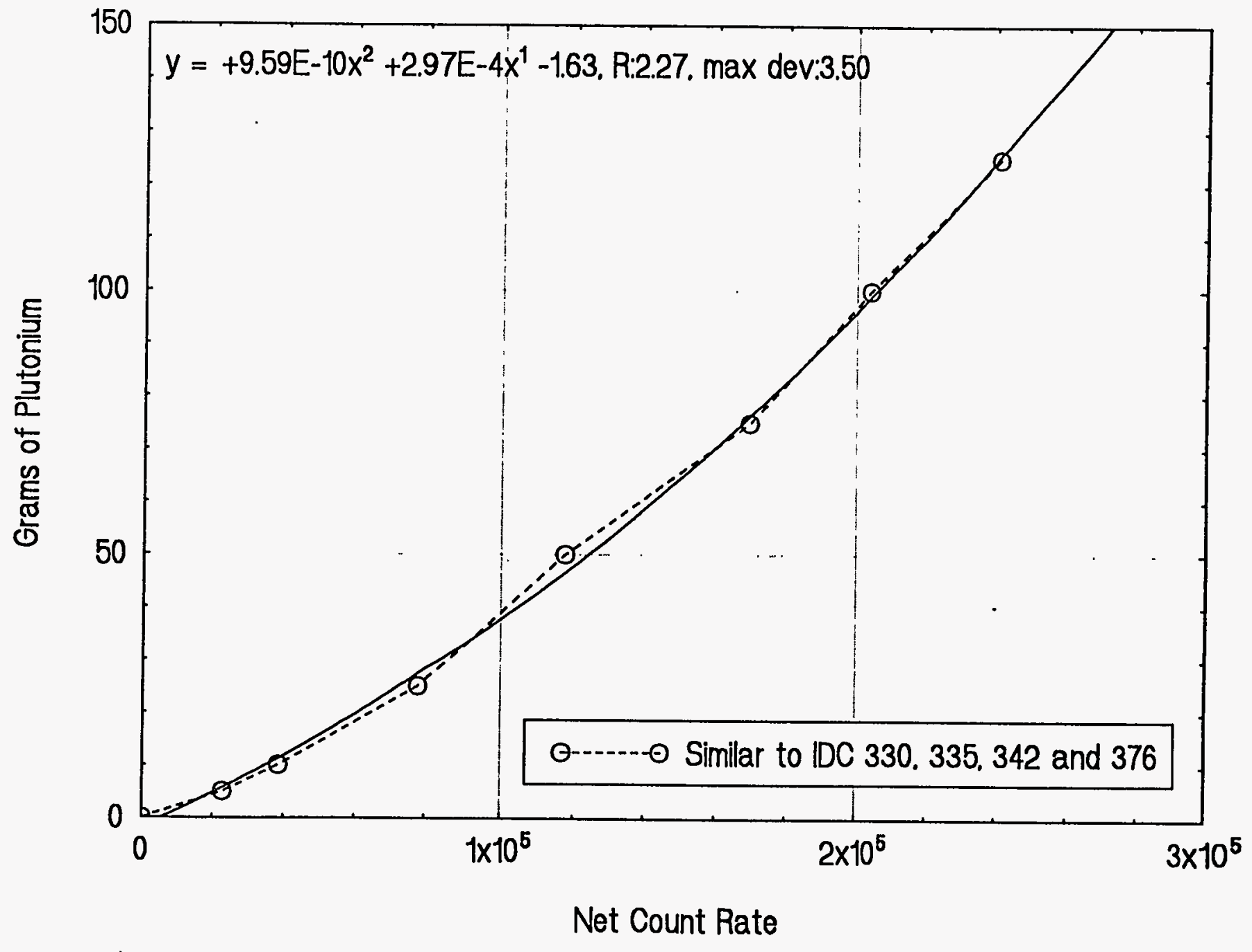




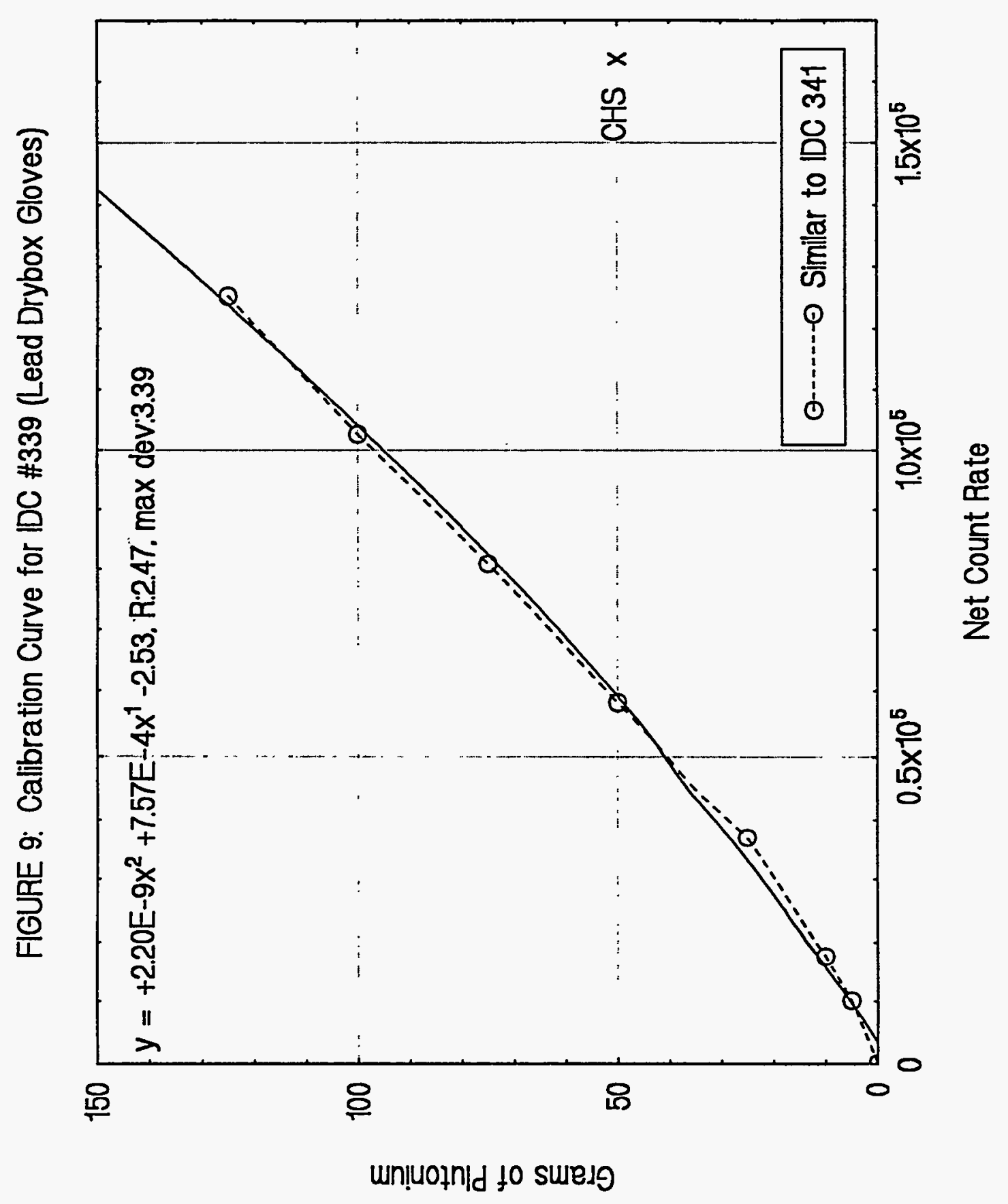




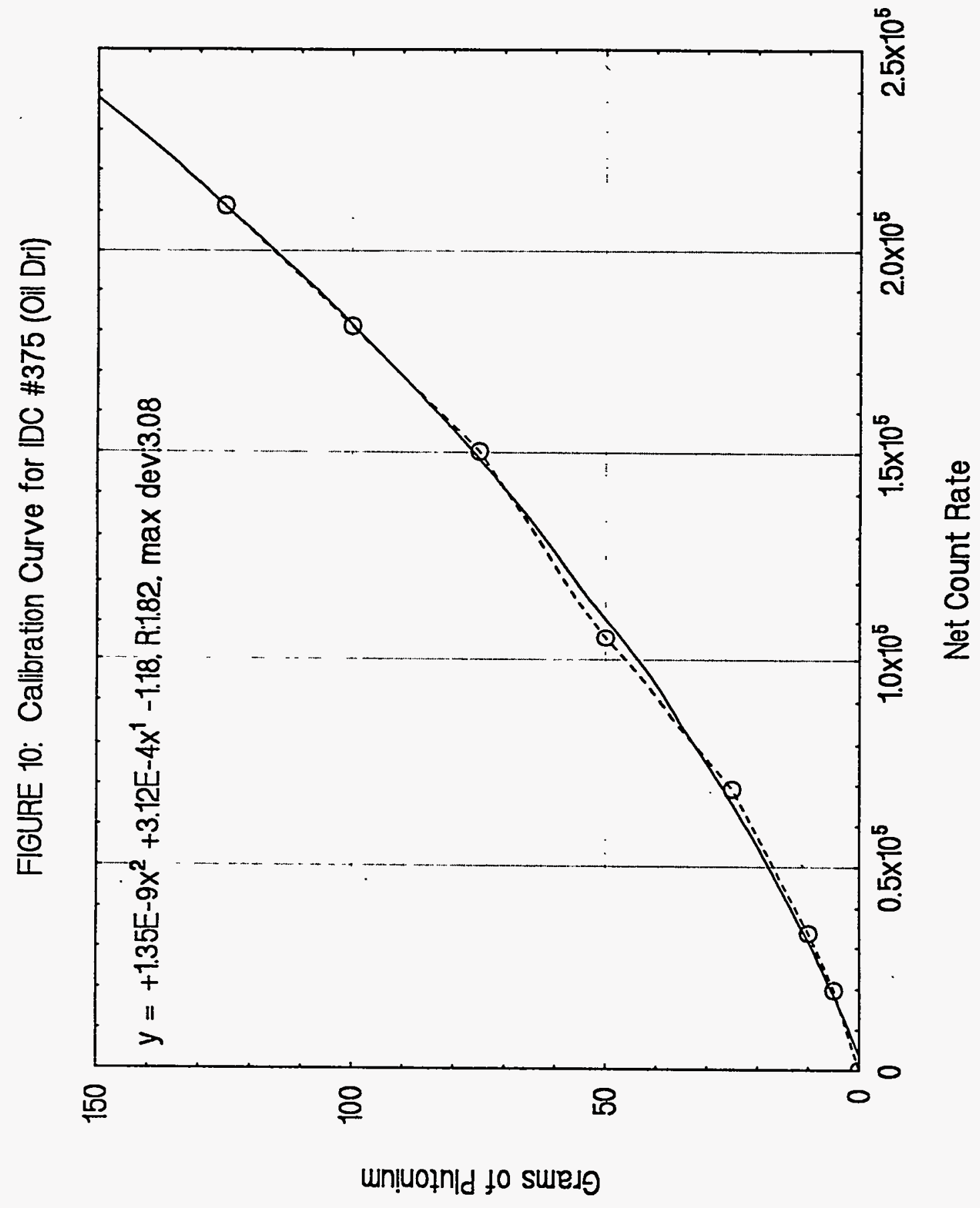




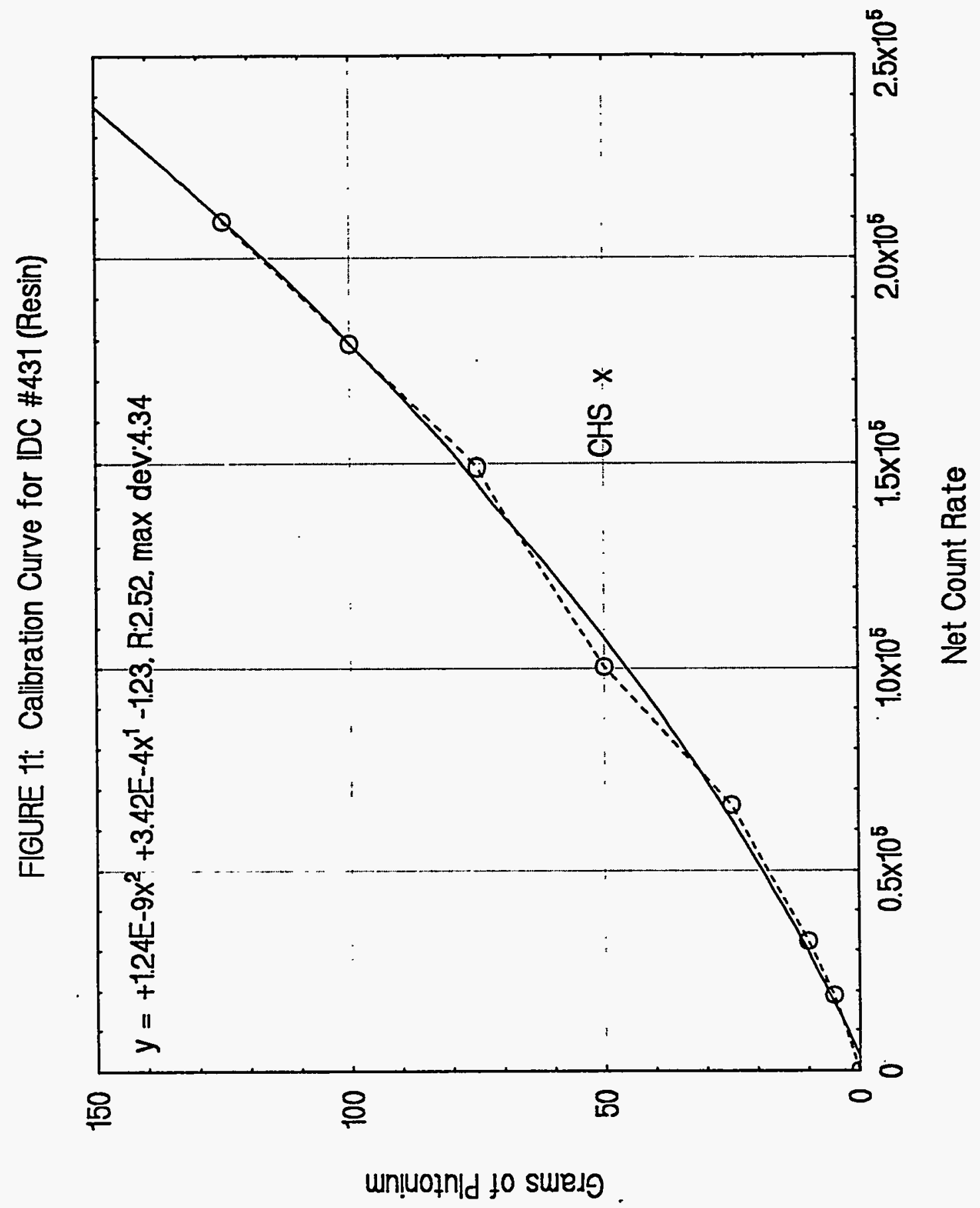




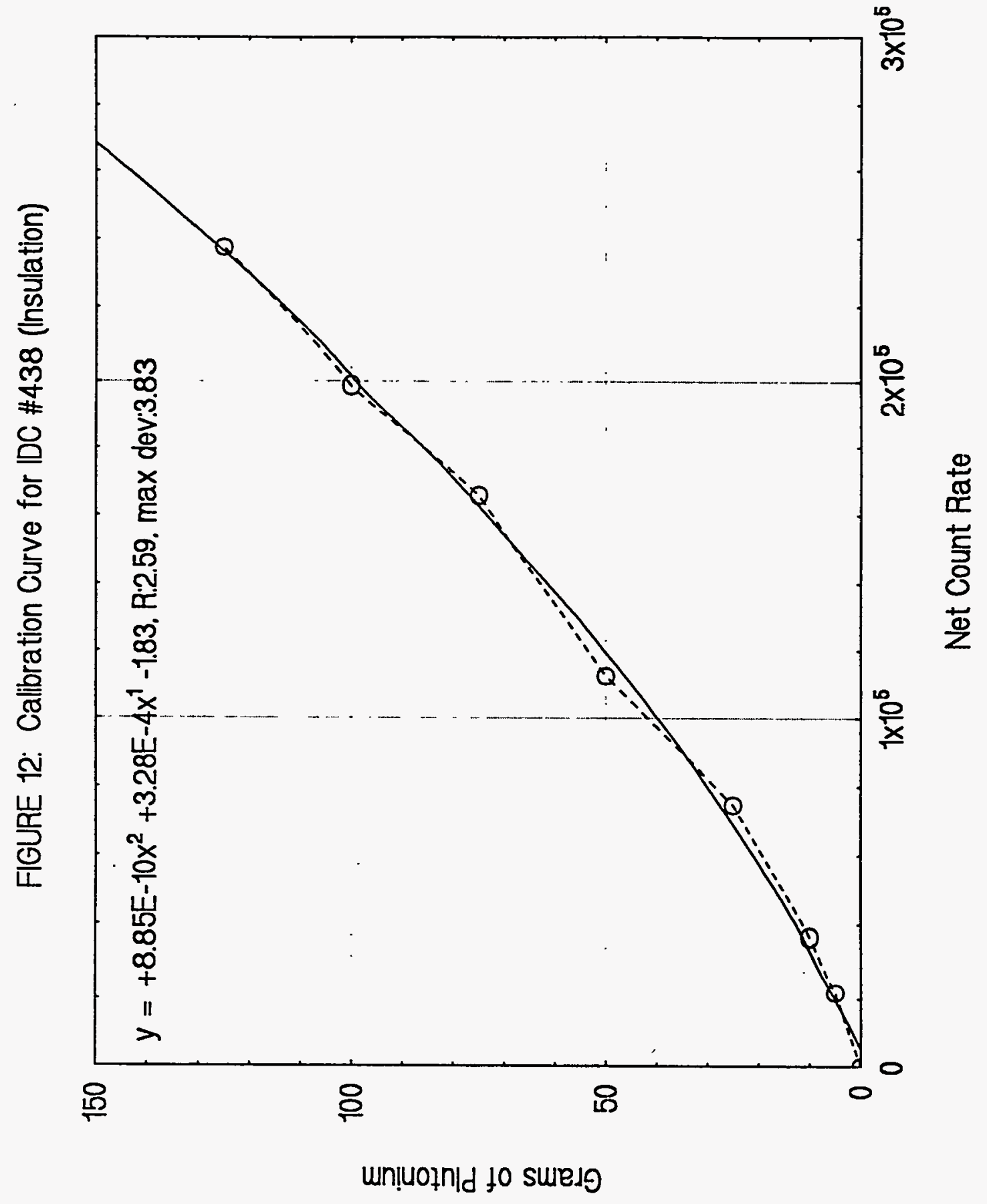




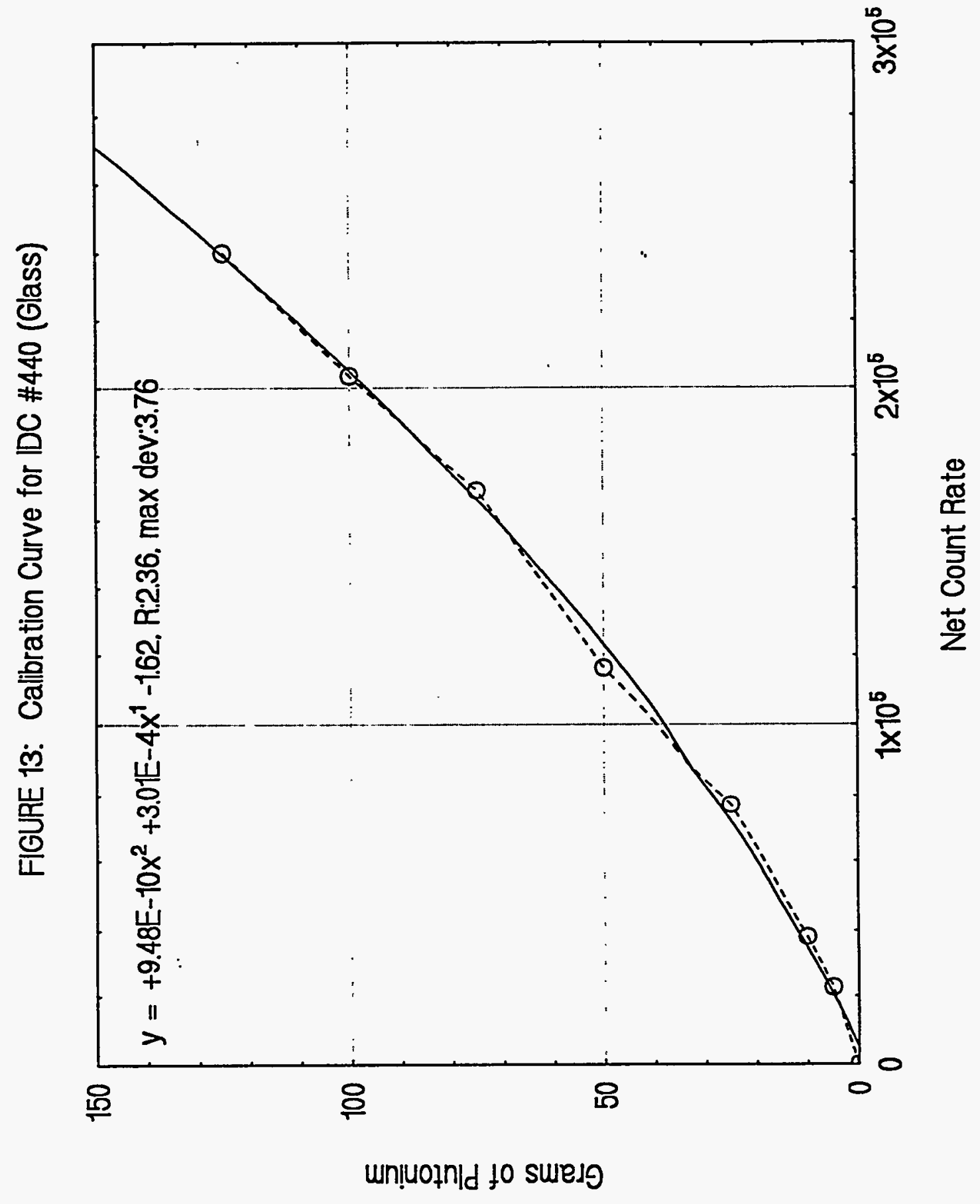




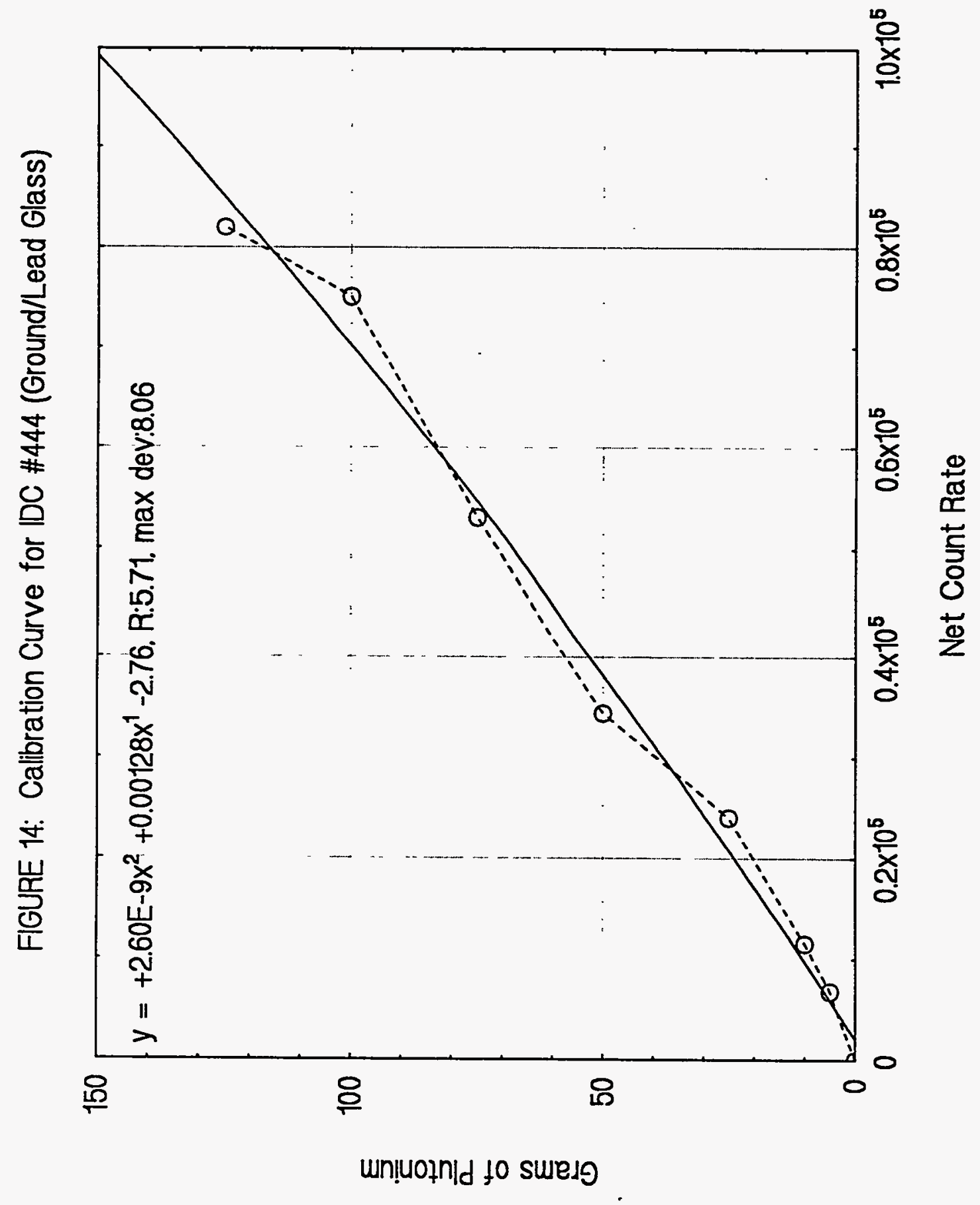




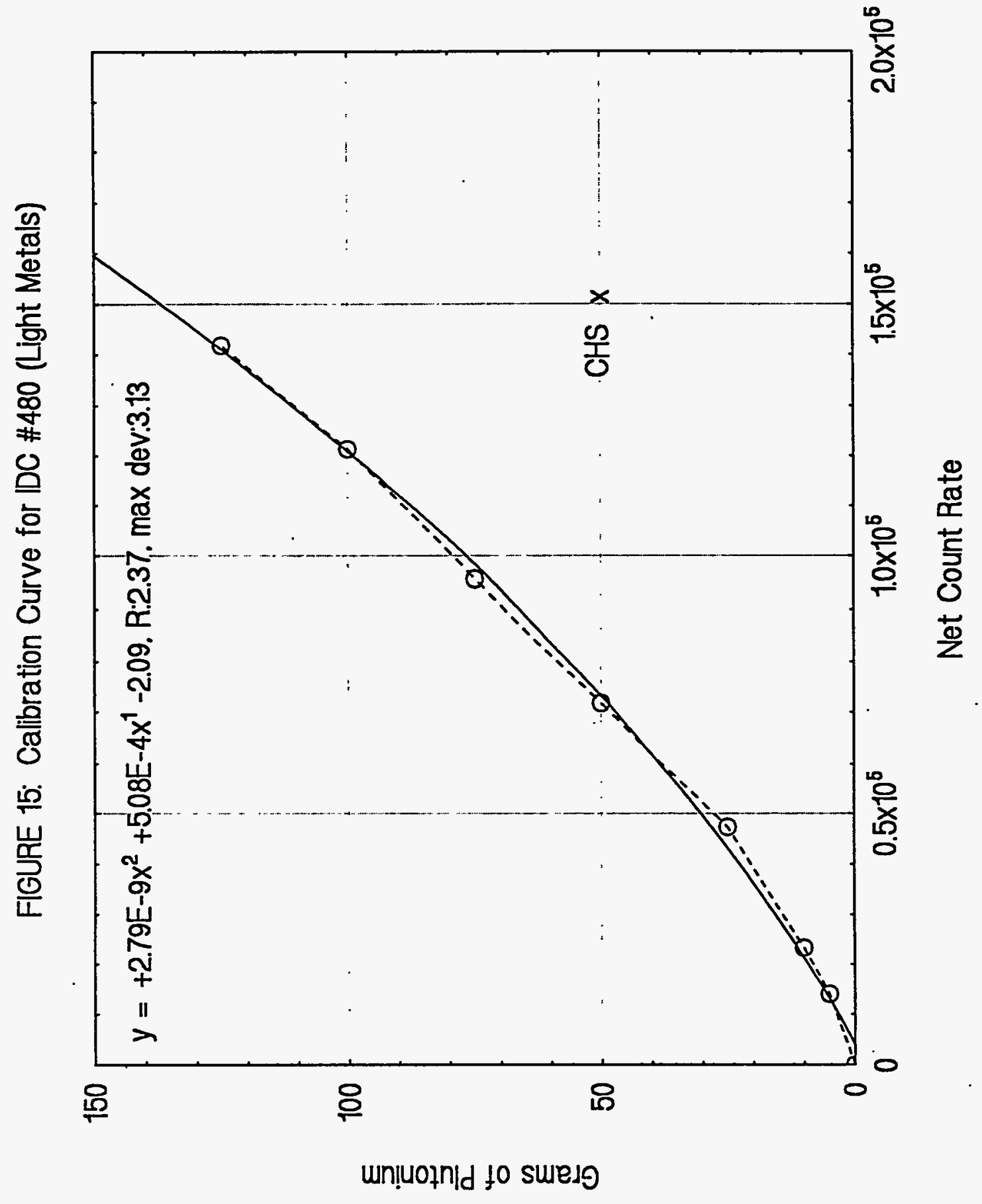


of these standards were compared with the similar matrix TES calibrations where TES standards were placed at the center in central tube of the clamshells with no $\mathrm{PuO}_{2}$ in the matrix. Measured count rates for the cHs standards are shown on the corresponding TES. calibration graphs.

\section{table 1: Clamshell Homogeneous Standards}

\begin{tabular}{|c|c|c|c|}
\hline$\frac{\text { IDC }}{\text { No. }}$ & $\begin{array}{l}\text { Matrix } \\
\text { Description }\end{array}$ & $\left.\mathrm{PuO}_{2}-\mathrm{g}\right)$ & $\begin{array}{l}\text { From TES } \\
\text { Calibration } \\
\text { Curve (g) }\end{array}$ \\
\hline 331 & Ful-flo Filters & $49.99 \pm 0.23$ & 117.0 \\
\hline 336 & Wet Combustibles & $49.99 \pm 0.23$ & 123.9 \\
\hline 337 & Poly, Tefion, PVC & $49.61 \pm 0.23$ & 150.2 \\
\hline 339 & Lead Gloves & $49.62 \pm 0.23$ & 184.1 \\
\hline 431 & Resin & $49.99 \pm 0.23$ & 96.3 \\
\hline 48 & Light Metals & $49.89 \pm 0.23$ & 140.5 \\
\hline
\end{tabular}

Data for eight available Can Counter standards (CCS), four each for IDC 331 and 338 , are given in Table 2. These CCSs, which had very high ${ }^{241} \mathrm{Am}$ content, were counted in the CGE. Their fissile material mass content estimations, using TES calibration curves for similar matrices, are also given in Table 2 . 


\section{TABLE 2: Can Counter Standards}

\begin{tabular}{|c|c|c|c|}
\hline$\frac{\text { IDC }}{\text { No. }}$ & $\begin{array}{l}\text { Matrix } \\
\text { Description }\end{array}$ & $\left.\mathrm{PuO}_{2}-\mathrm{g}\right)$ & $\frac{\frac{\text { From TES }}{\text { Calibration }}}{\text { Curve (g) }}$ \\
\hline \multirow[t]{4}{*}{$33 i$} & Ful-flo Filters & 0.00 & 0.0 \\
\hline & & $19.9 \pm 0.6$ & 51.5 \\
\hline & & $65.7 \pm 0.4$ & 155.1 \\
\hline & & $138.3 \pm 0.4$ & 251.3 \\
\hline \multirow[t]{4}{*}{338} & Filter Media & $10.6 \pm 0.3$ & 28.7 \\
\hline & & $15.3 \pm 0.4$ & 46.9 \\
\hline & & $27.4 \pm 0.8$ & 77.7 \\
\hline & & $46.2 \pm 0.5$ & 139.2 \\
\hline
\end{tabular}

\subsection{CGE SOURCE POSITION CHARACTERIZATION STUDY}

A 50 gram TES was positioned at 27 positions around various clamshells filled with different IDC matrix materials. Position numbers were as indicated in Figure 2. Counting was performed for 10 seconds and net count rates were determined in each case. Plots in Figures 16-28 show observed detector responses as a function of the source position around different IDC clamshells.

Data from these plots were used to estimate measurement uncertainties due to source position inside the package or source geometry effect. In a clamshell, for a particular matrix, the ratios between the highest count rate position divided by the center position (Position one) count rate and the center position count rate divided by the lowest count rate position were determined, and a geometry factor or 'G-Factor' for the IDC was calculated as the larger of the two ratios. This factor is used as a multiplier to the $\mathrm{Pu}$ mass estimated from the TES calibration curves for different IDCs. 


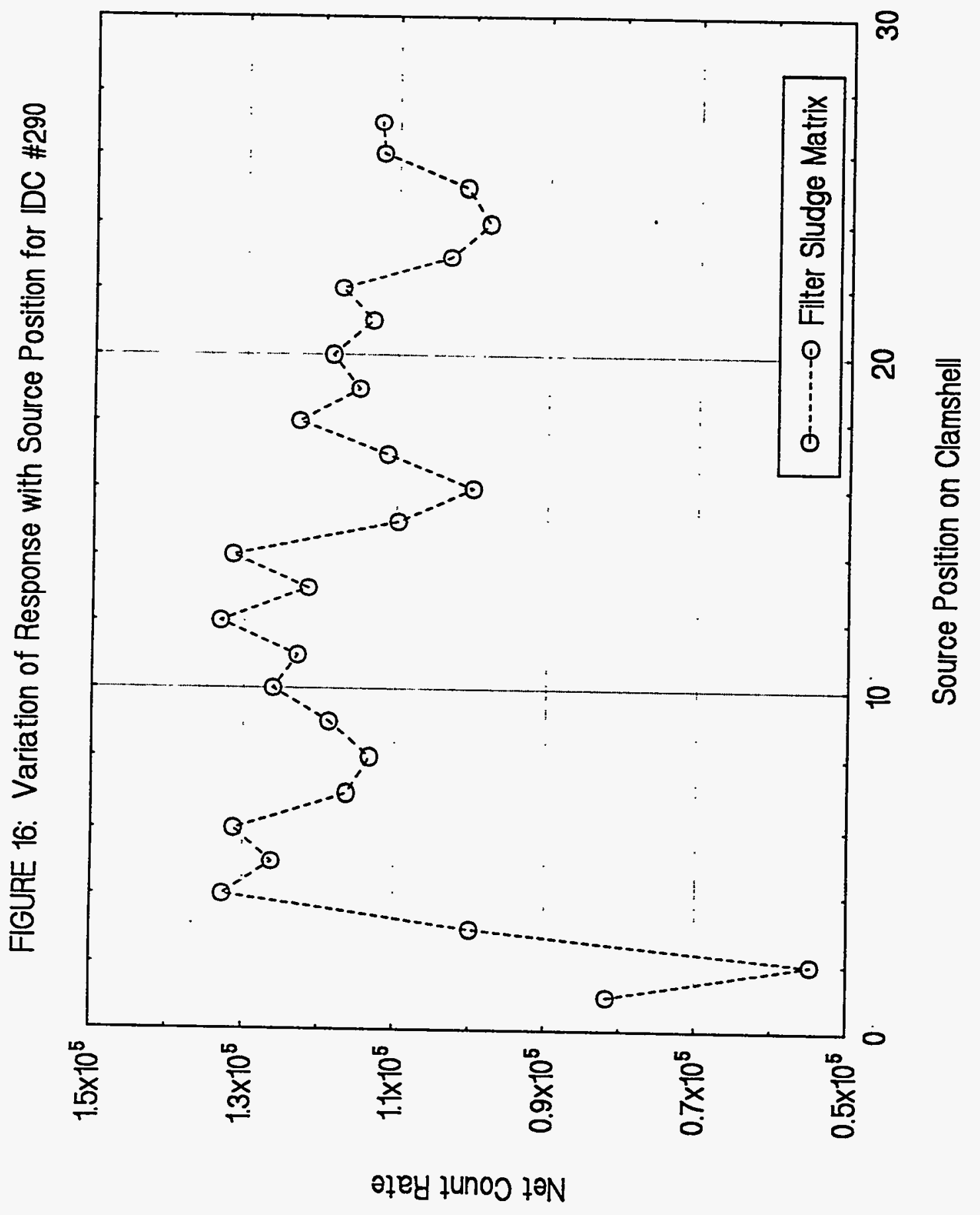




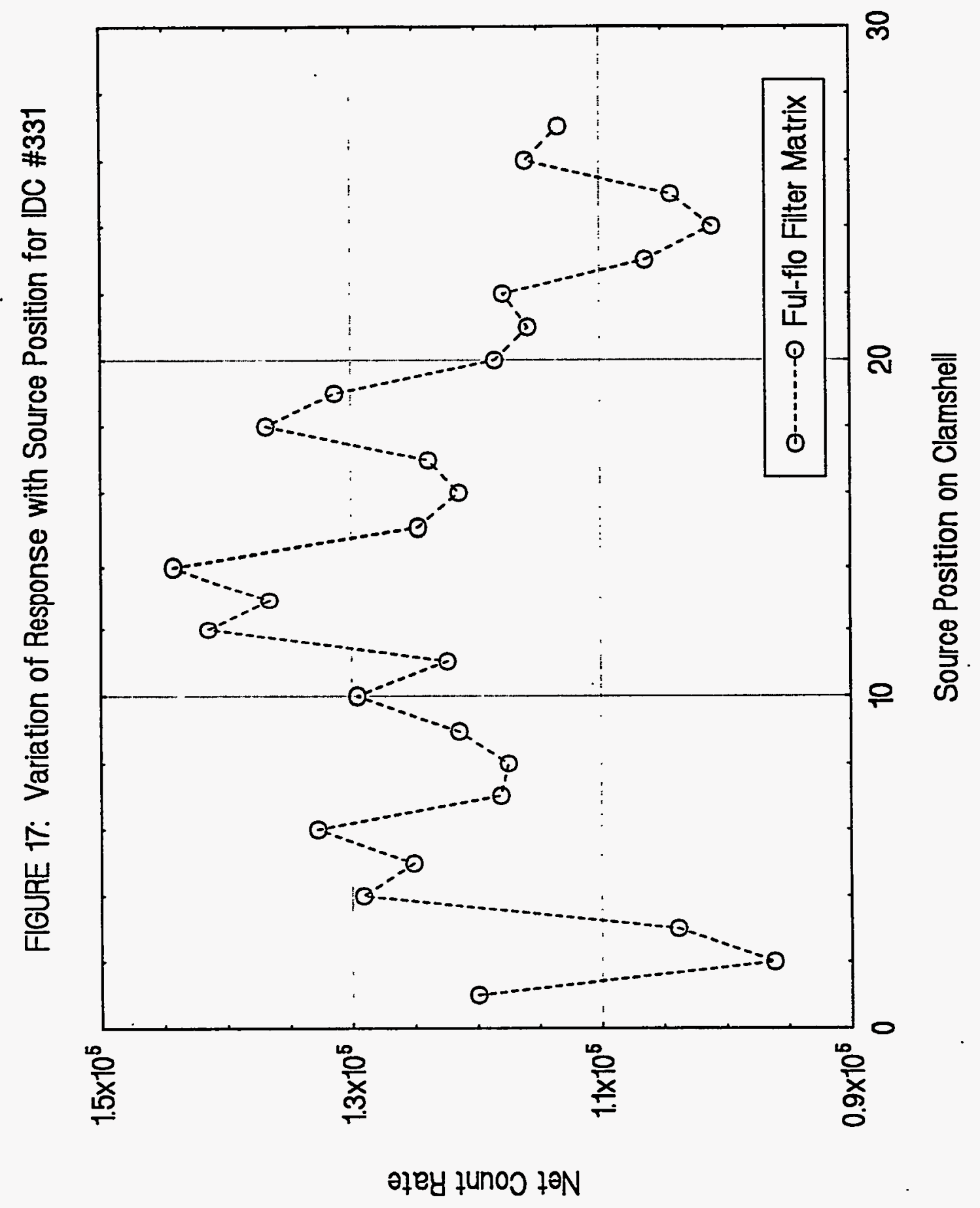




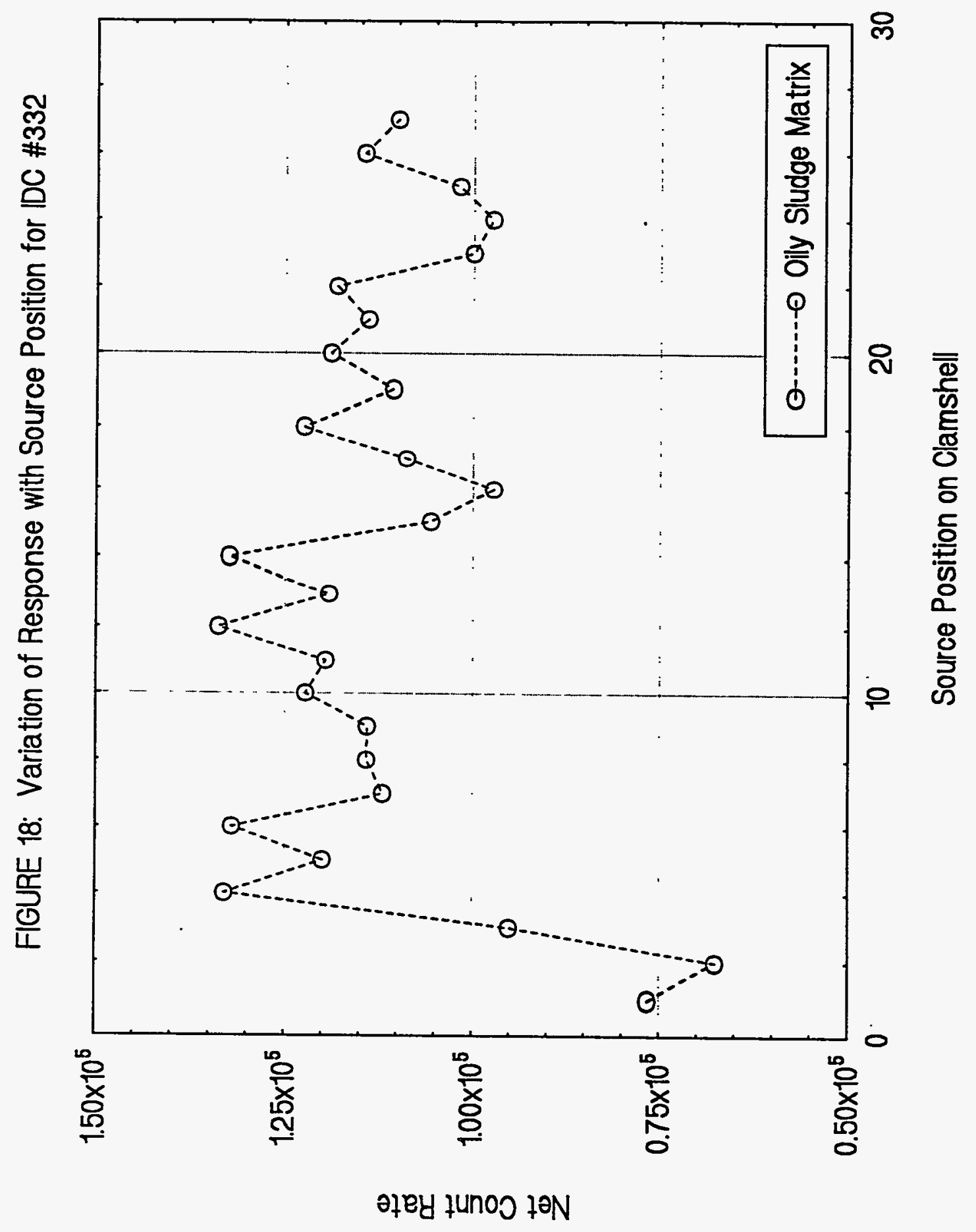




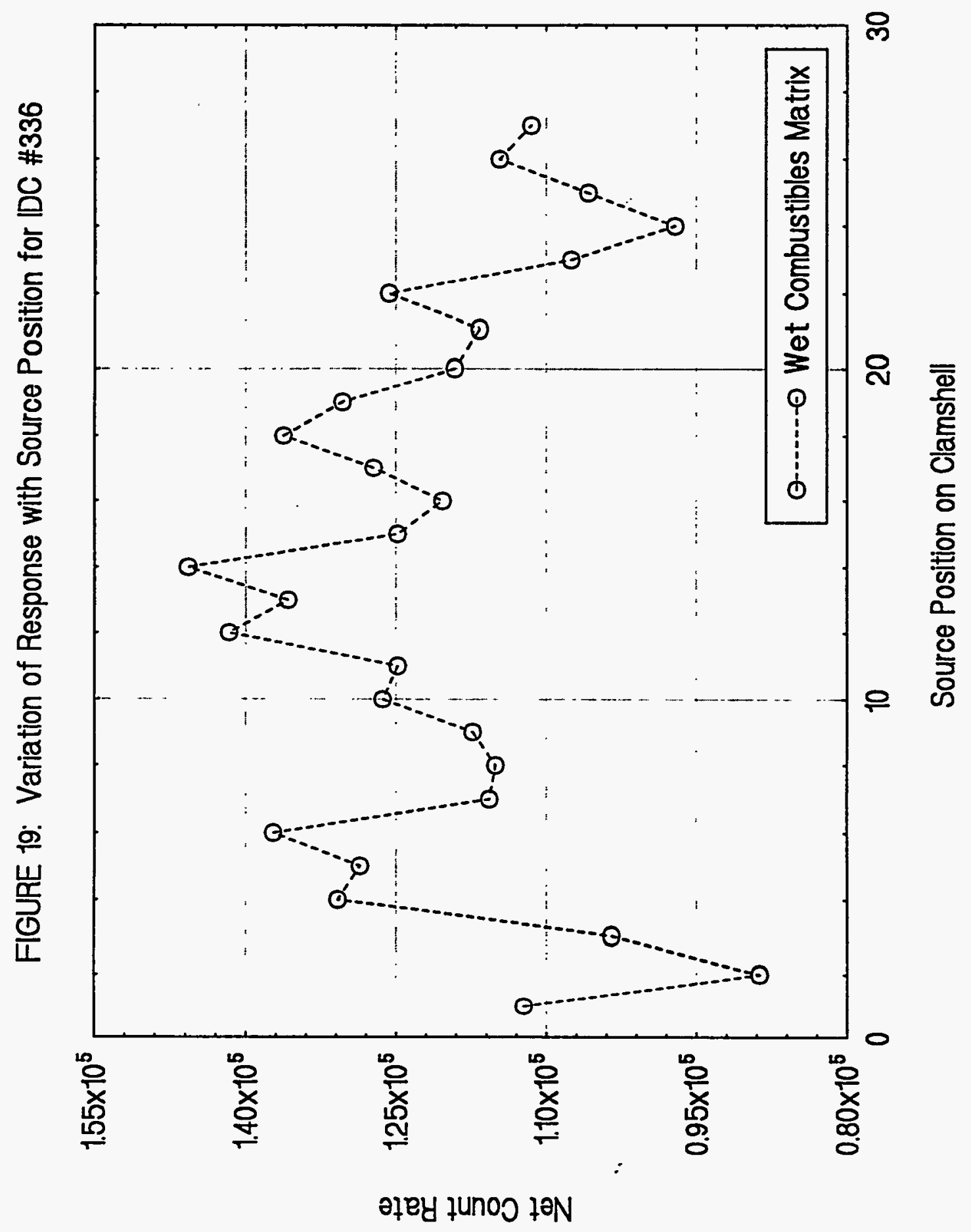




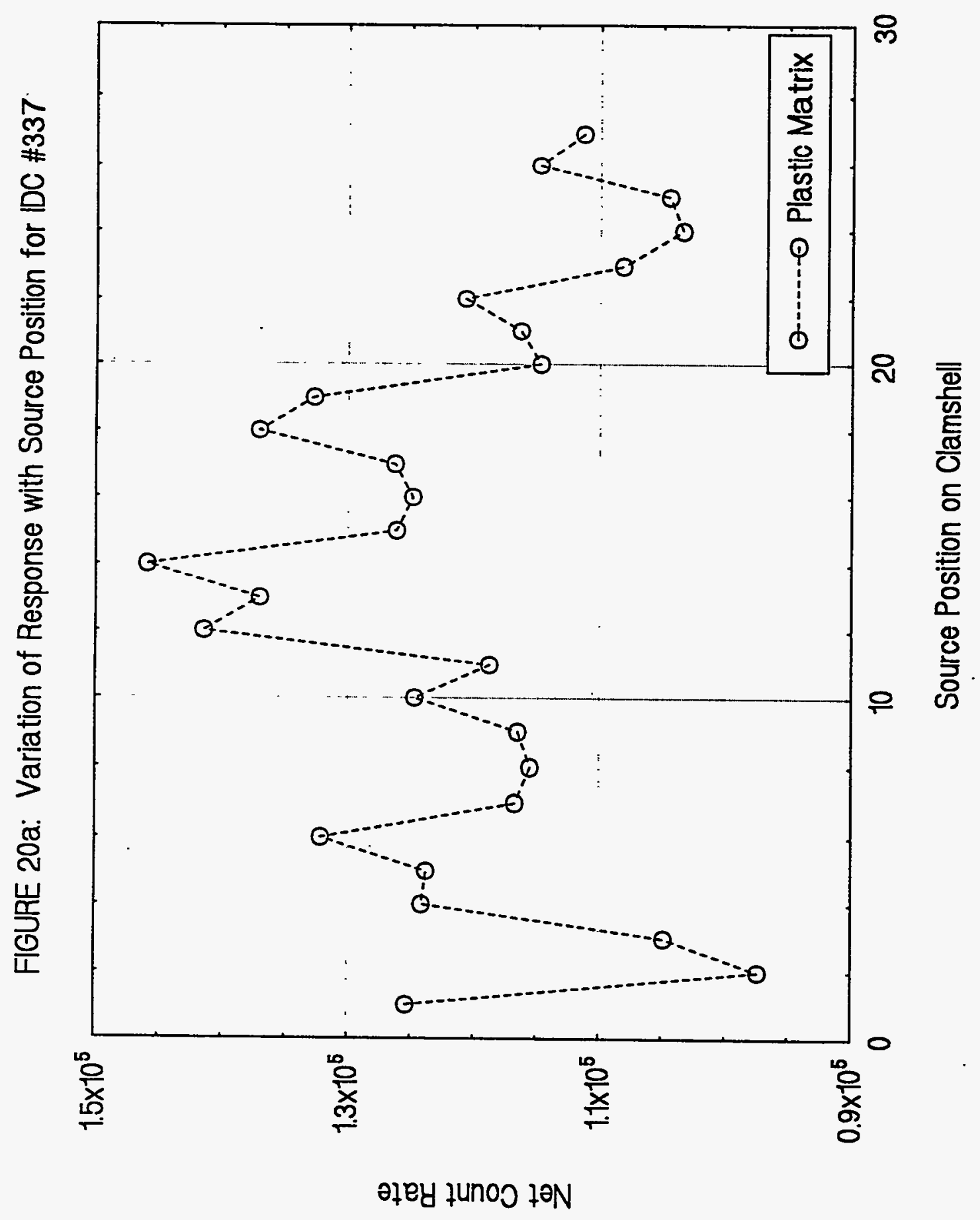




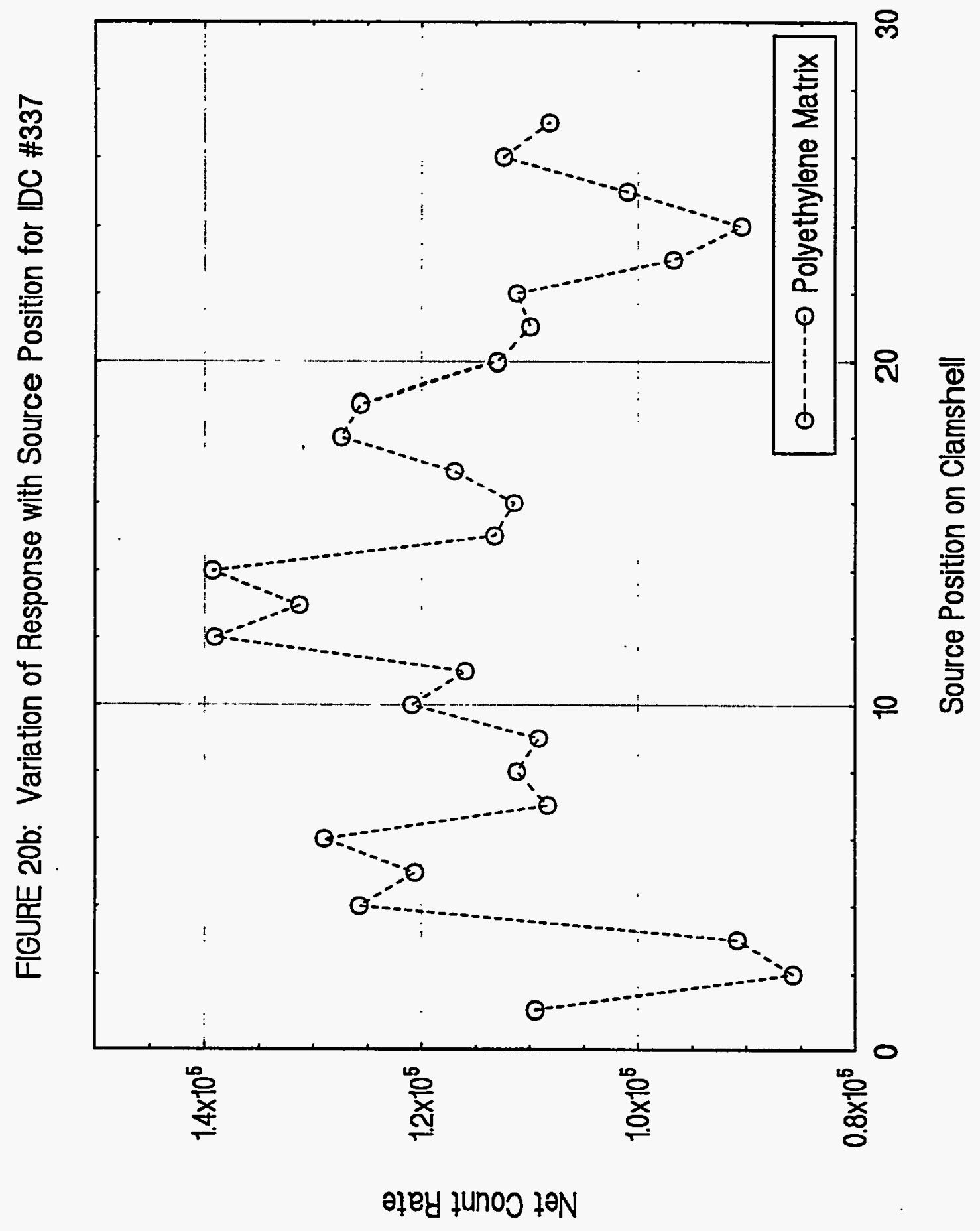




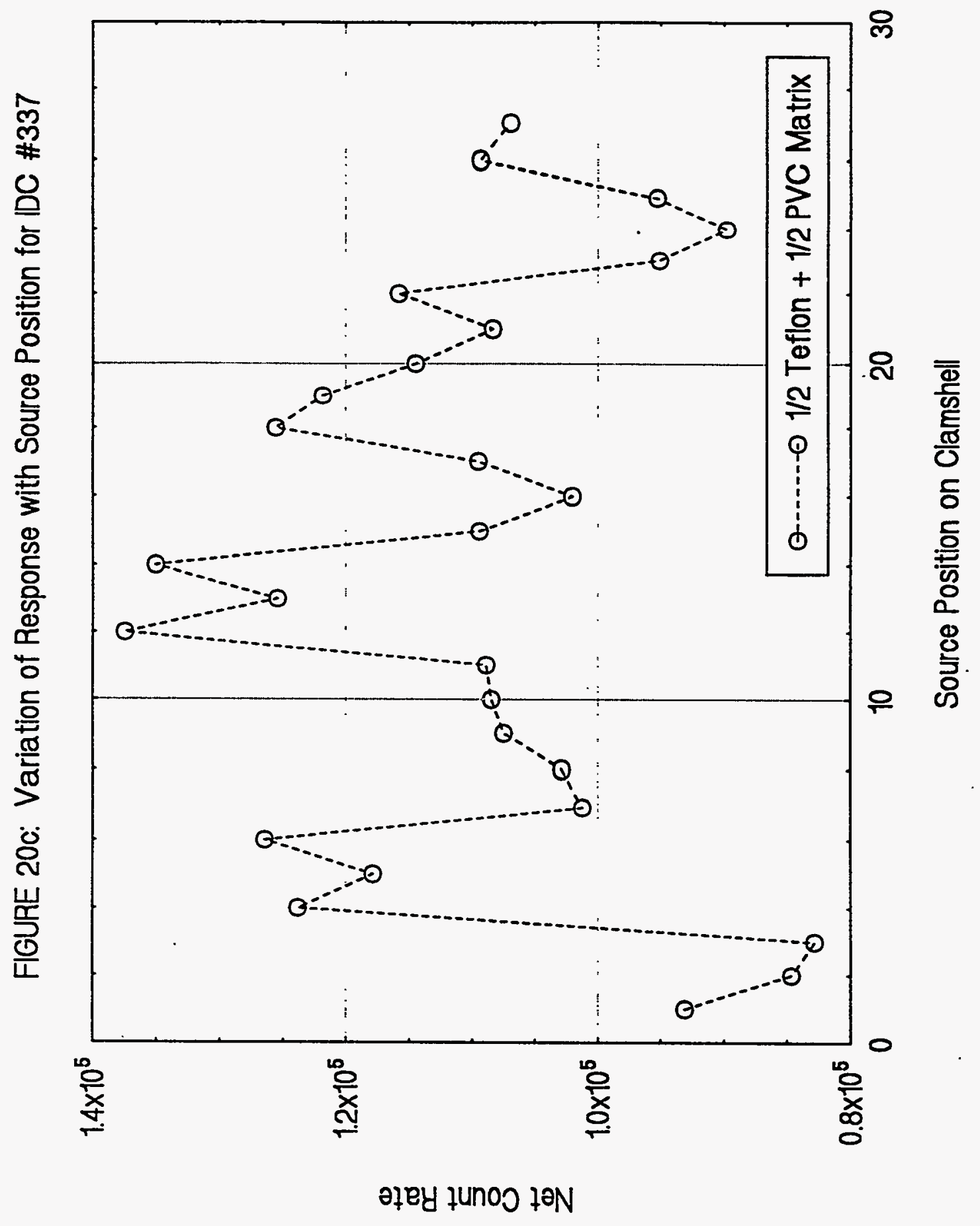




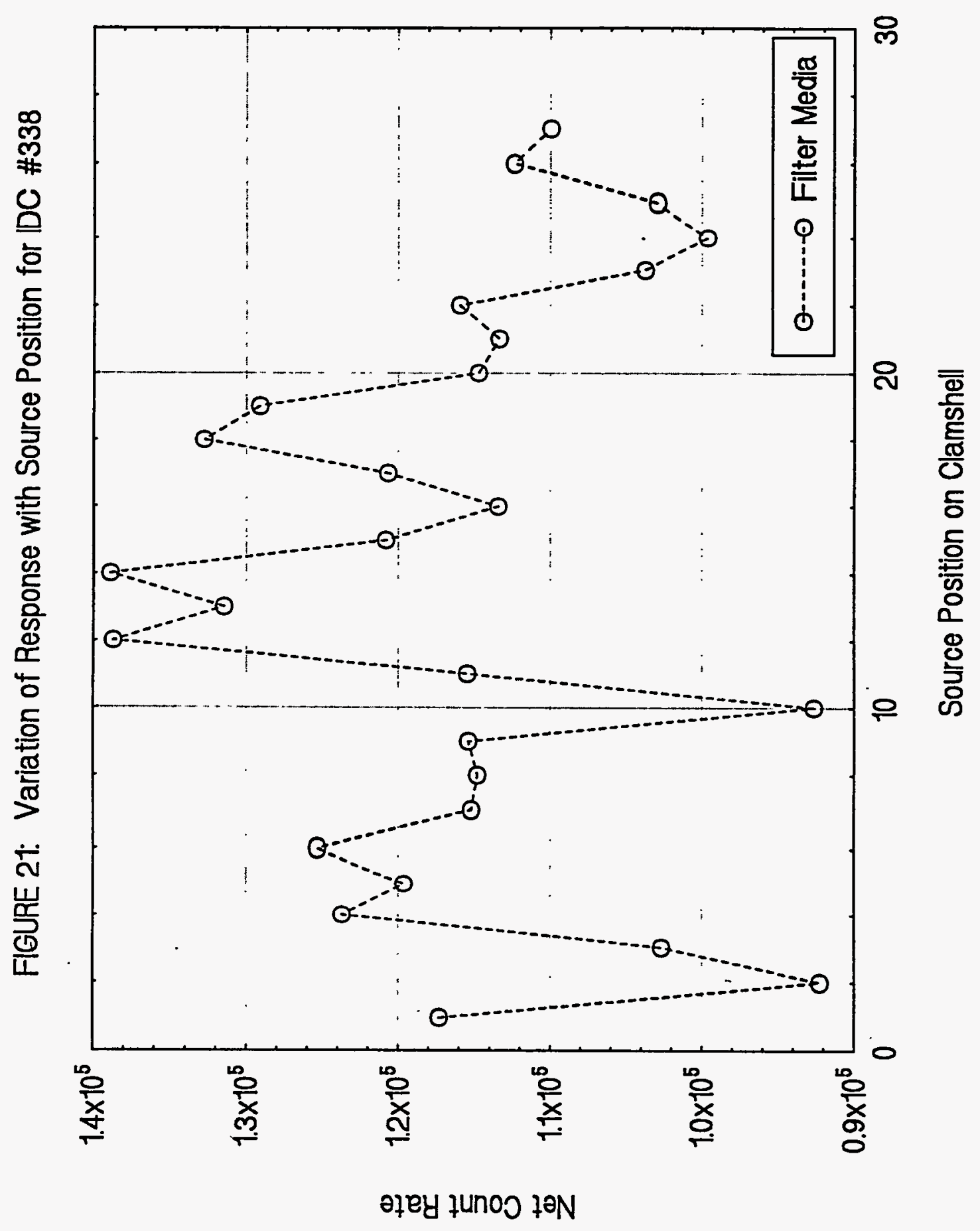


FIGURE 22: Variation of Response with Source Position for IDC \#339

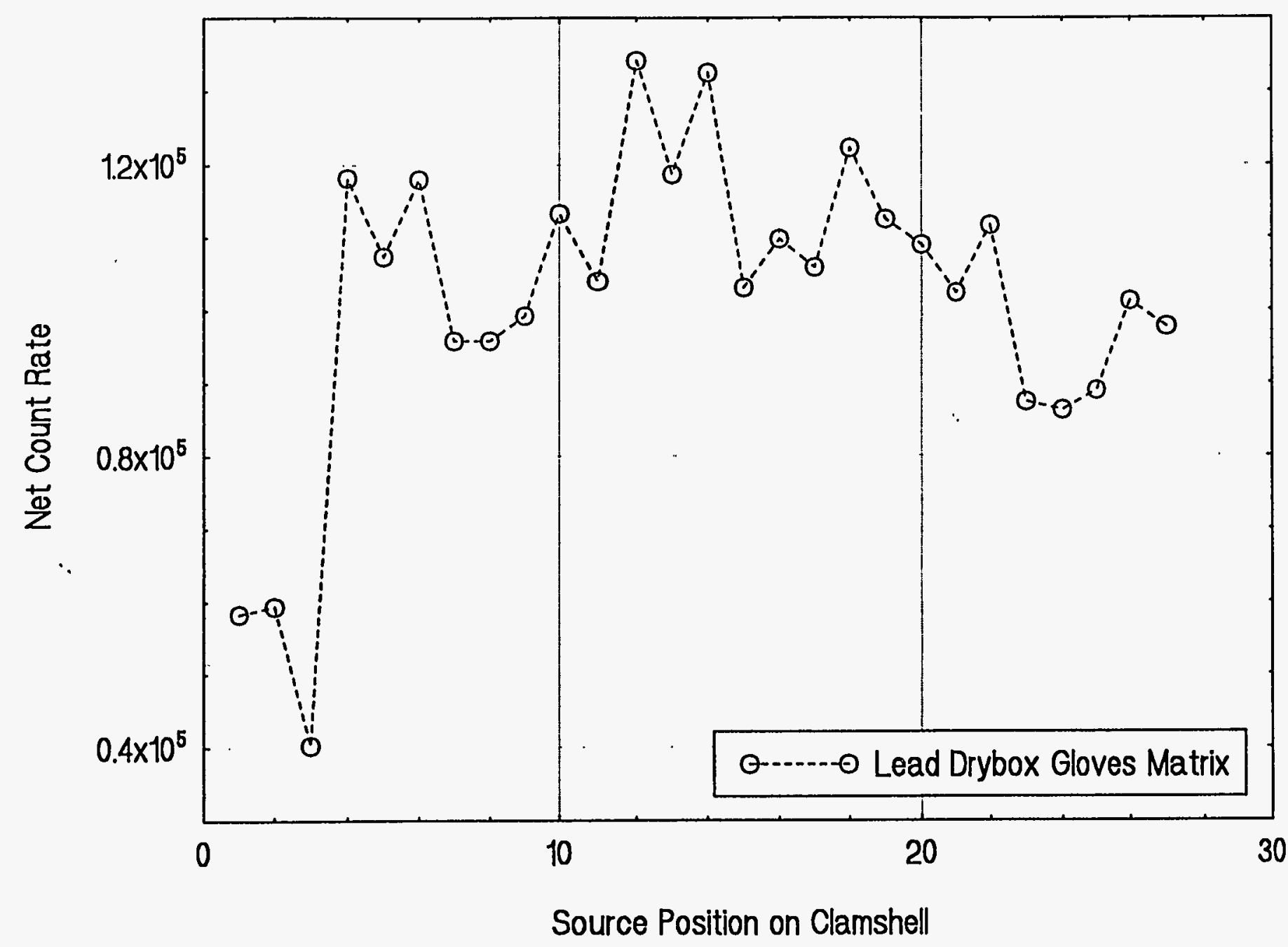




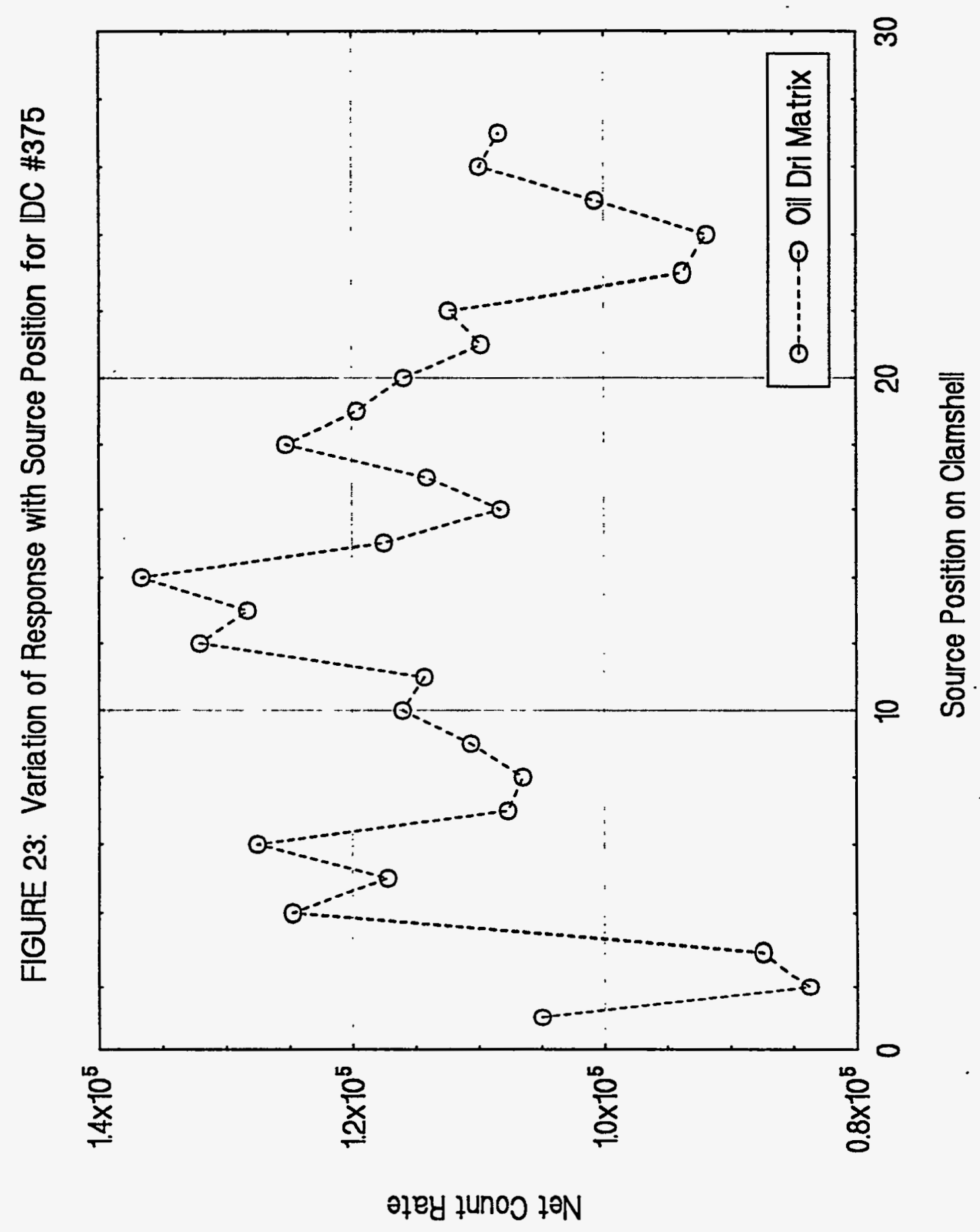




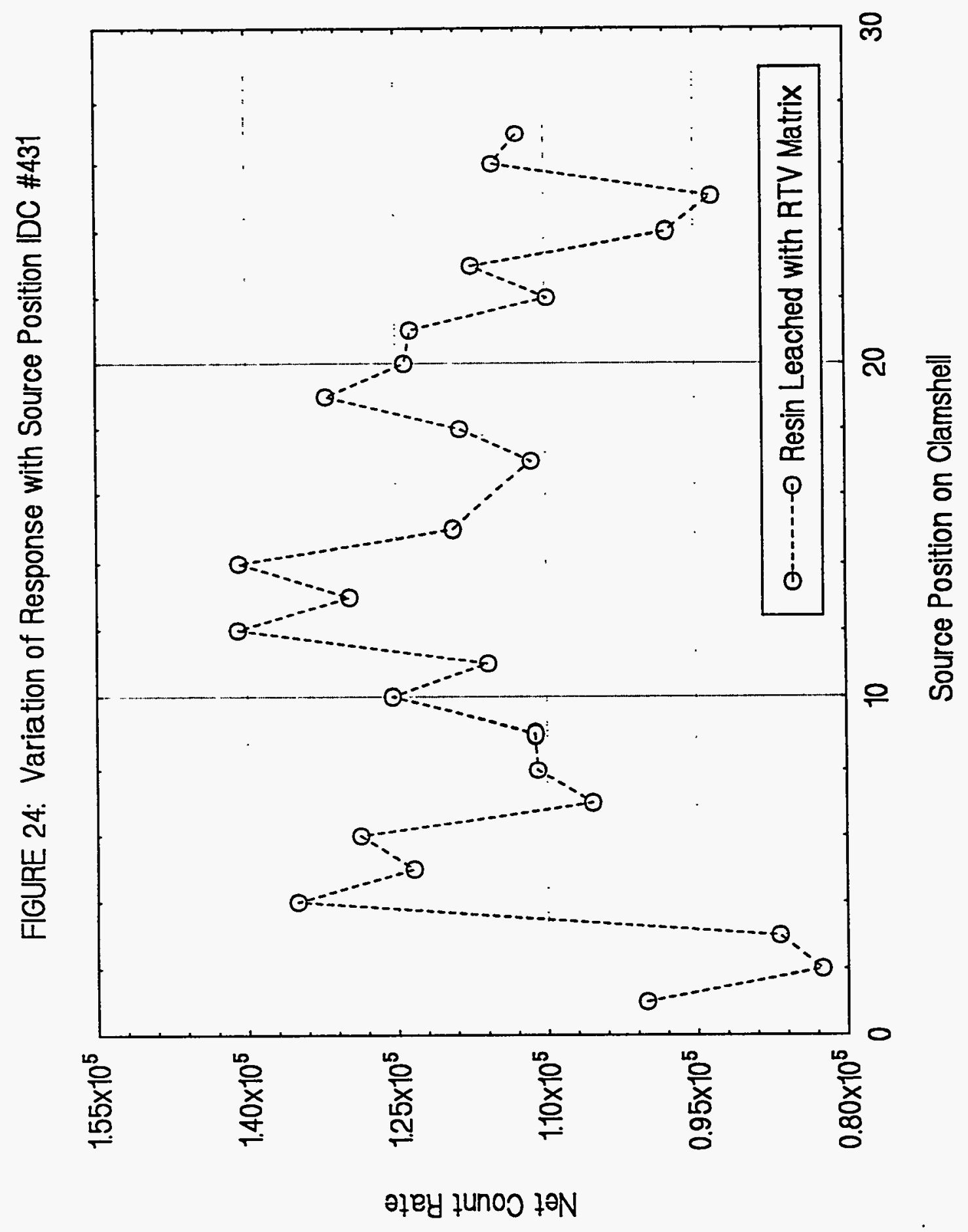




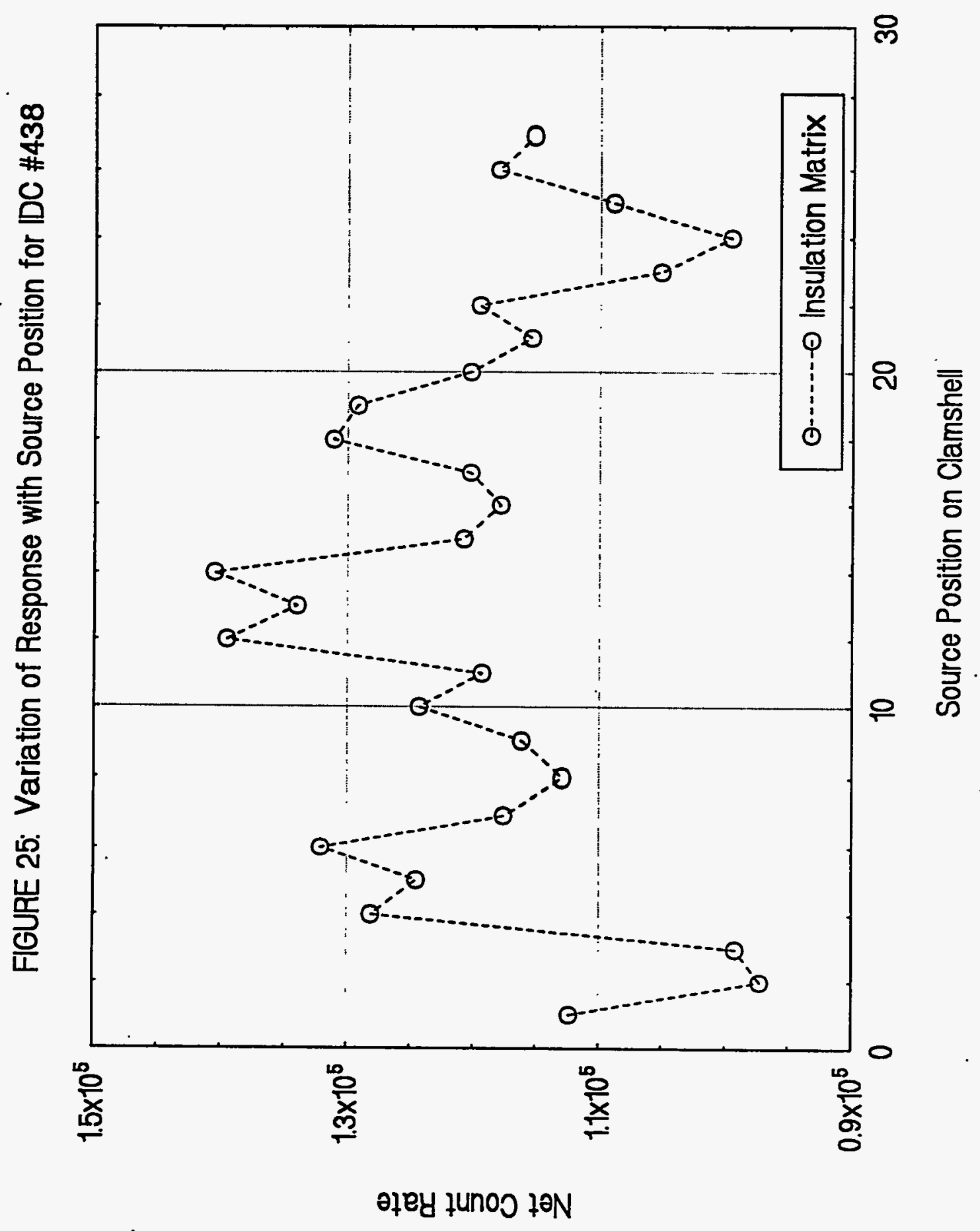




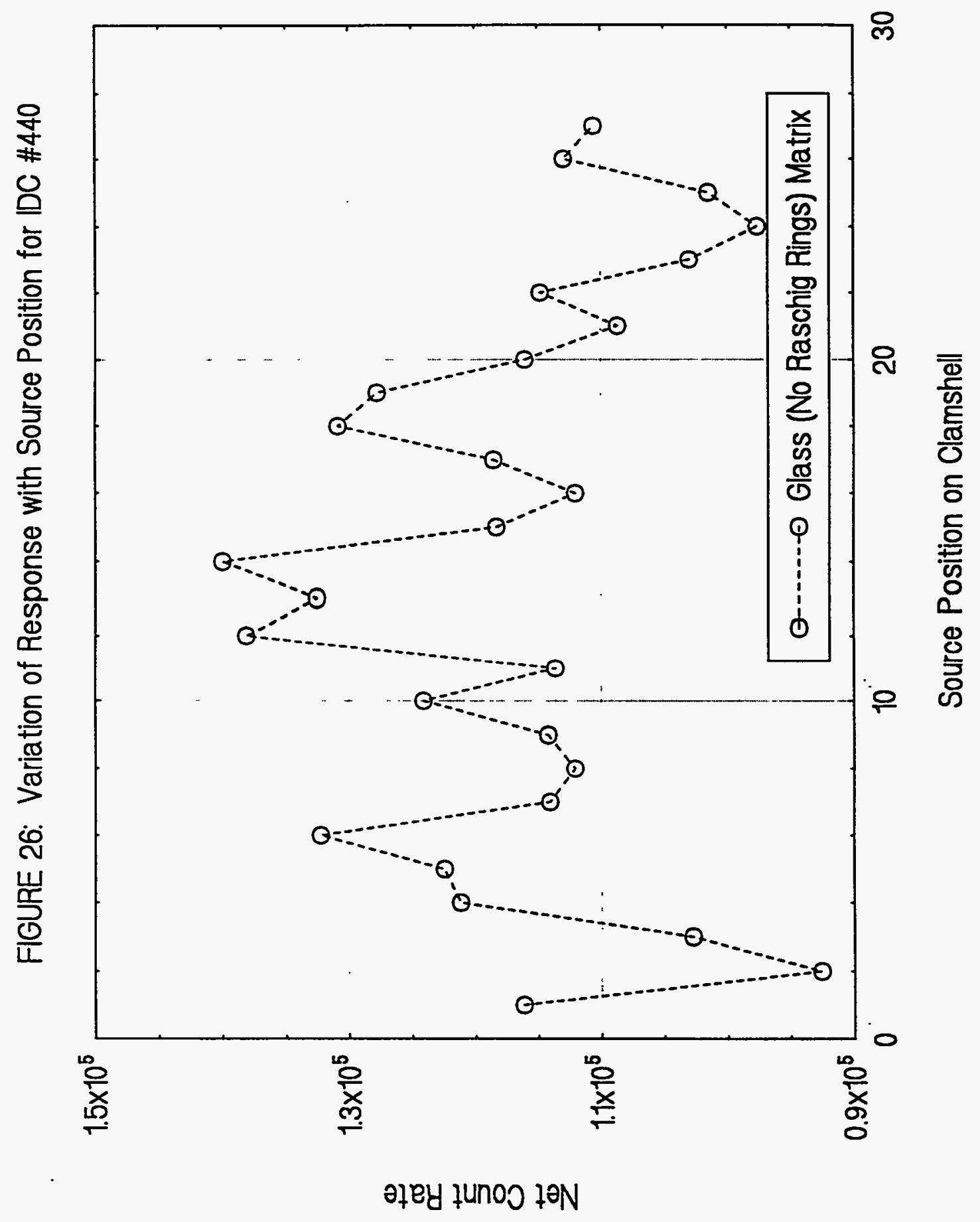




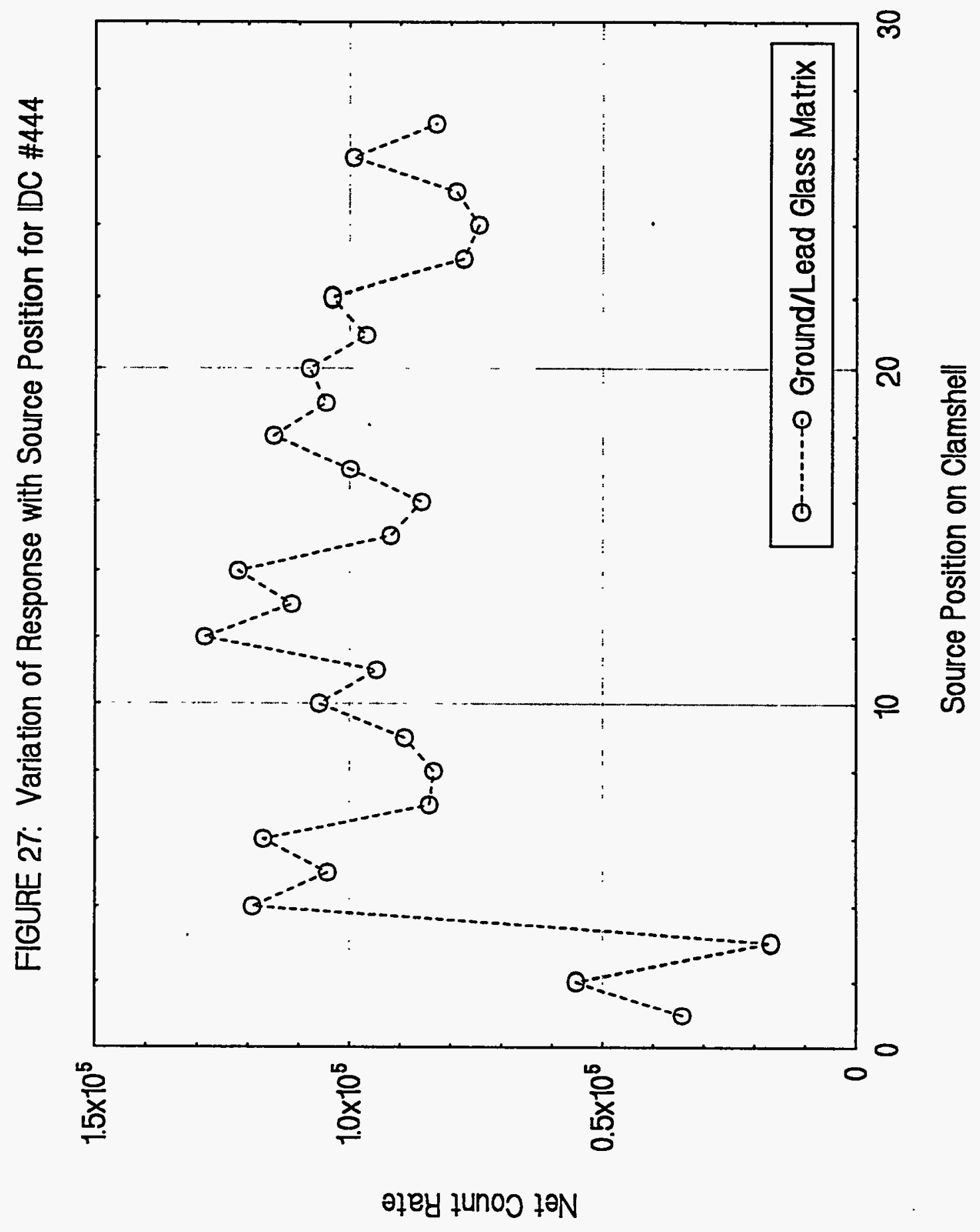


FIGURE 28: Variation of Response with Source Position for IDC \#480

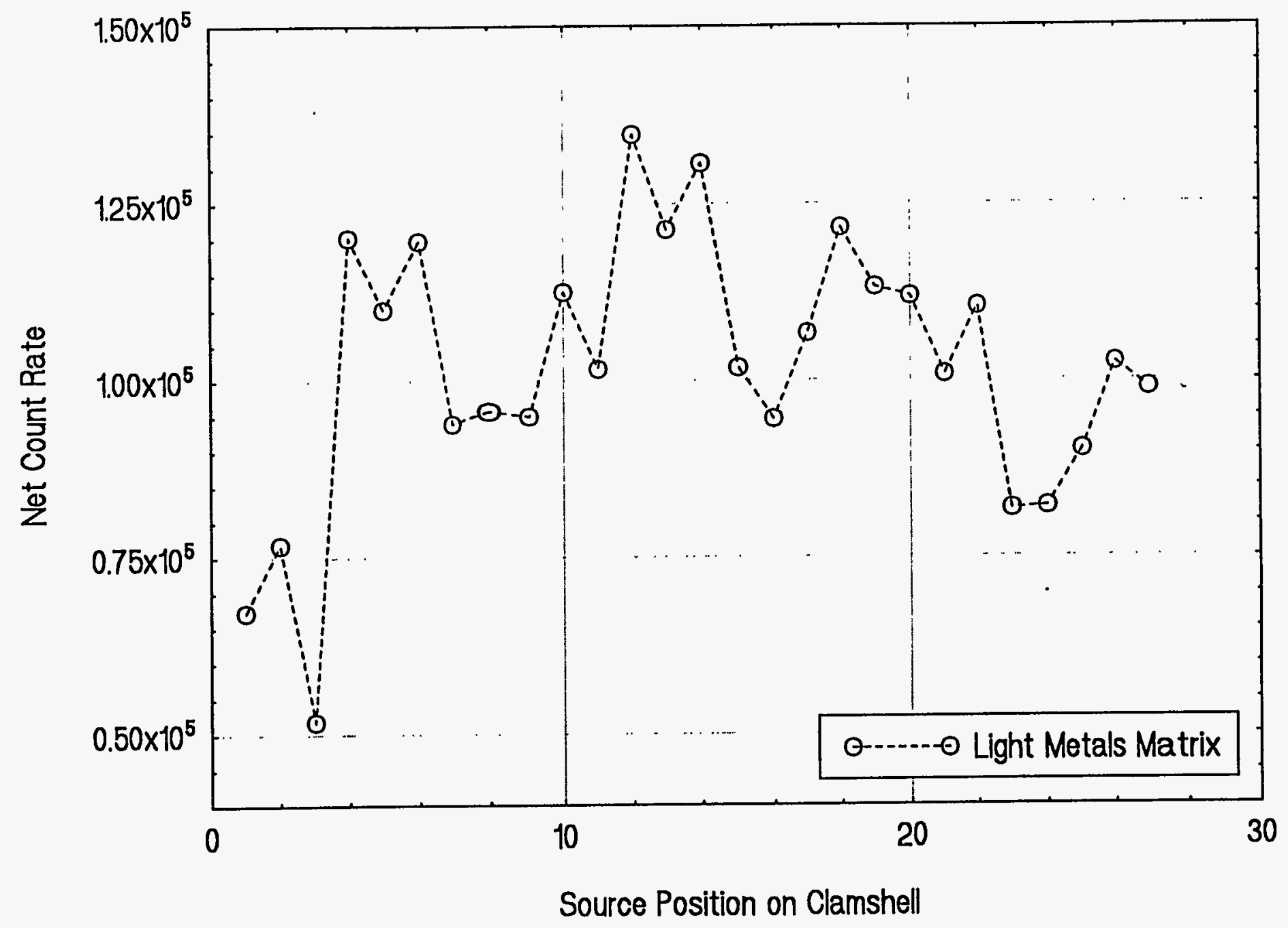




\subsection{OTHER CHARACTERIZATION STUDIES PERFORMED ON CGE}

Matrix absorption effects were characterized with the TES and CHS standards within various matrices constructed from synthetic waste forms. Encapsulated ${ }^{241} \mathrm{Am}$ standards were also used to quantify the response contributions from the $\mathrm{PuO}_{2}$ standards anticipated with actual waste packages as discussed in section 4.1 .

Background measurements as well as measurements using empty clamshells (no source but filled with different matrices) were also performed. These measurements indicate the lower detection limits that can be expected for a proposed operating location.

\section{OPERATION OF THE CGE}

A procedure "Chamber Gram Estimator Building 771," 4-B28-CGE-001, has been issued for operation of the CGE. When an operator places a waste package inside the sample chamber and follows the procedure for utilizing the measurement program, the technique dependence that was of concern with the PGE is eliminated and the risk of exposure to the operator is significantly reduced.

After the operator powers up the computer and the CGE, a batch file automatically displays a Main Menu and the operator is then directed to follow the prompts as outlined in the operating procedure. Associated with the operating program is a data file that contains calibration data for each IDC accounting for matrix absorption, a factor accounting for the $\mathrm{Pu}$ distribution in the matrix (geometry factor), and a time of estimation for each IDC (Table 3). These parameter data values were determined using TES sources for different matrices based on the expected waste characteristics. Within the operating program, there is an option for the operator to print out the results of the estimate that could be attached to the Waste/Residue Traveler form for the waste drum that is being loaded. 


\section{table 3: Calibration Data File}

IDC

No.

290

330

331

332

335

336

337

338

339

341

342

375

376

431

438

440

444

480 $\frac{a}{\left(x 10^{-9}\right)}$

$\frac{b}{\left(x 10^{-4}\right)}$

1.16

5.26

2.97

2.88

5.53

2.97

2.86

4.14

2.97

7.57

7.57

2.97

3.19

1.31

0.959

2.97

3.42

3.28

3.01

1.28

5.08

2.79

2.60

$-2.76$

$-2.09$

$-1.29$

$-1.63$

$-1.23$

$-1.83$ $\begin{array}{ll}\text { Geometry } & \text { Count Time } \\ \text { Factor } & \underline{\text { (seconds) }}\end{array}$

1.63

100

1.27

50

1.25

100

1.75

100

1.27

50

1.30

50

1.48

50

1.27

50

2.30

100

2.30

100

1.27

50

1.30

50

1.27

50

1.41

50

1.25

50

1.25

50

3.77

100

2.00

100 


\section{RESULTS AND DISCUSSIONS}

Due to the limited gamma energy resolution of plastic scintillation detectors, electronic discrimination provides no significant optimization of the ${ }^{239} \mathrm{Pu}$ to ${ }^{241} \mathrm{Am}$ response ratio, and very precise electronic adjustments were not necessary. An internal 1/8" $\mathrm{Cu}$ shield thickness, in conjunction with threshold settings, was found to be sufficient to prevent significant ${ }^{241} \mathrm{Am}$ response due to the concentrations inherent in the calibration standards used. Also, the external 3/8" lead shield thicknesses was adequate to reduce the background response for all practical purposes even in the ${ }^{241} \mathrm{Am}$ process environment in Building 771.

With the present CGE, a few grams of ${ }^{239} \mathrm{Pu}$ could be distinguished above background in light IDC matrix samples. The CGE has a limited response contribution from ${ }^{241} \mathrm{Am}$ at concentrations of 1,000 ppm at the chosen operating region.

It is evident from the data that the TES calibration curves in Figures 3-15, when used for unknown samples give very conservative estimates of the fissile mass contents. The estimates are about a factor of 2 to 4 overestimation of fissile mass for the homogeneously distributed fissile matrices (CHS). This is due to the construction differences of the TES and cHS sources. In the case of TES standards, absorption by the 1/4" aluminum tube thickness (total source and mounting tube thicknesses) and $\mathrm{PuO}_{2}$ self-absorption due to compactness of the fissile material, the photon flux reaching the detectors is greatly reduced. In the cHs sources, on the other hand, the material is thinly distributed and there is very little, if any, self-absorption; hence the production of a higher count rate for the same amount of fissile material.

In actual practice, a line generated waste package may not have a homogeneous distribution or a point-source form of the fissile material. Moreover, it is required that the CGE should not underestimate the fissile contents of the package to avoid violating criticality safety limits. It is therefore acceptable to overestimate and not to underestimate the fissile material contents. Although, it is helpful to limit overestimation tolerances, errors such as material matrix and self-absorption are unavoidable with instruments like the CGE.

Basic limitations of passive gamma measurement instruments for fissile material mass determination apply to hand-held instruments as well as counting chamber estimators. Their responses are highly dependent on the density of the fissile fraction of the waste form. Appropriate choice of calibration standard matrices is important to avoid both underestimation and over conservatism. Matrix effects 
can be determined empirically, however, estimation uncertainties are large, particularly for higher density IDCs.

\section{CONCLUSIONS AND RECOMMENDATIONS}

The CGE provides the advantages over the Ludlum 12-12 PGE presently in use. The CGE is easy to operate, does not require manipulation/rotation of the sample during measurement, and provides a discrete display value free of rate meter response-time effects or the need for visual averaging. The chamber shielding effectively eliminates gamma exposure to operators from waste packages during the measurement process. Response variations due to sample geometry are significantly less than with hand-held instruments, particularly, for the low density matrix samples appropriate for estimation.

Fissile material estimation techniques need to be viewed as a supplement to a Non-destructive Assay (NDA) program, and are useful when the rate of waste package generation exceeds the throughput of accountability measurements through NDA systems. In terms of priority, fissile packaging operations should be reviewed for the adequacy of available assay systems. If assay systems are available and a fissile packaging program is expected to generate samples more rapidly than can be conveniently certified, it may be reasonable to consider continuing the practice of estimation. However, estimation results should be routinely compared with assay values to insure the validity of tolerances predicted for various waste forms. NDA specialists should oversee estimation programs to ensure at least subjective equivalency between waste and calibration matrices. In cases where estimation is appropriate and samples typically exceed a few inches in thickness or contribute significant gamma exposure, a counting chamber design should be pursued.

\section{FUTURE WORK}

If estimation techniques are appropriate for future operation, e.g., liquid stabilization and thermal stabilization, and additional units become desirable, the next generation of counting chambers should be investigated and implemented. Chambers now are available with thicker external shielding, larger detectors completely enclosing the sample volume (one detector in all six walls giving close to true $4 \pi$ geometry) and reduced chamber 
dimensions. The increased detector surface area will improve sample response and geometry effects (G-Factors), and the additional shielding and reduced sample volume will reduce background. These parameter improvements will optimize sensitivity of measurement.

Additional efforts to correlate existing standards to waste matrices, to fabricate additional standards more representative of waste forms, and to better define the tolerances associated with waste variables remain a priority for estimation programs.

9. REFERENCE

1. Dulco, G. B. and Balmer, D. K., "Investigation of Portable Gram Estimators," Rocky Flats Plant, January 1992, Unpublished. 
APPENDIX A

PHOTOGRAPHS OF THE CGE SETUP 

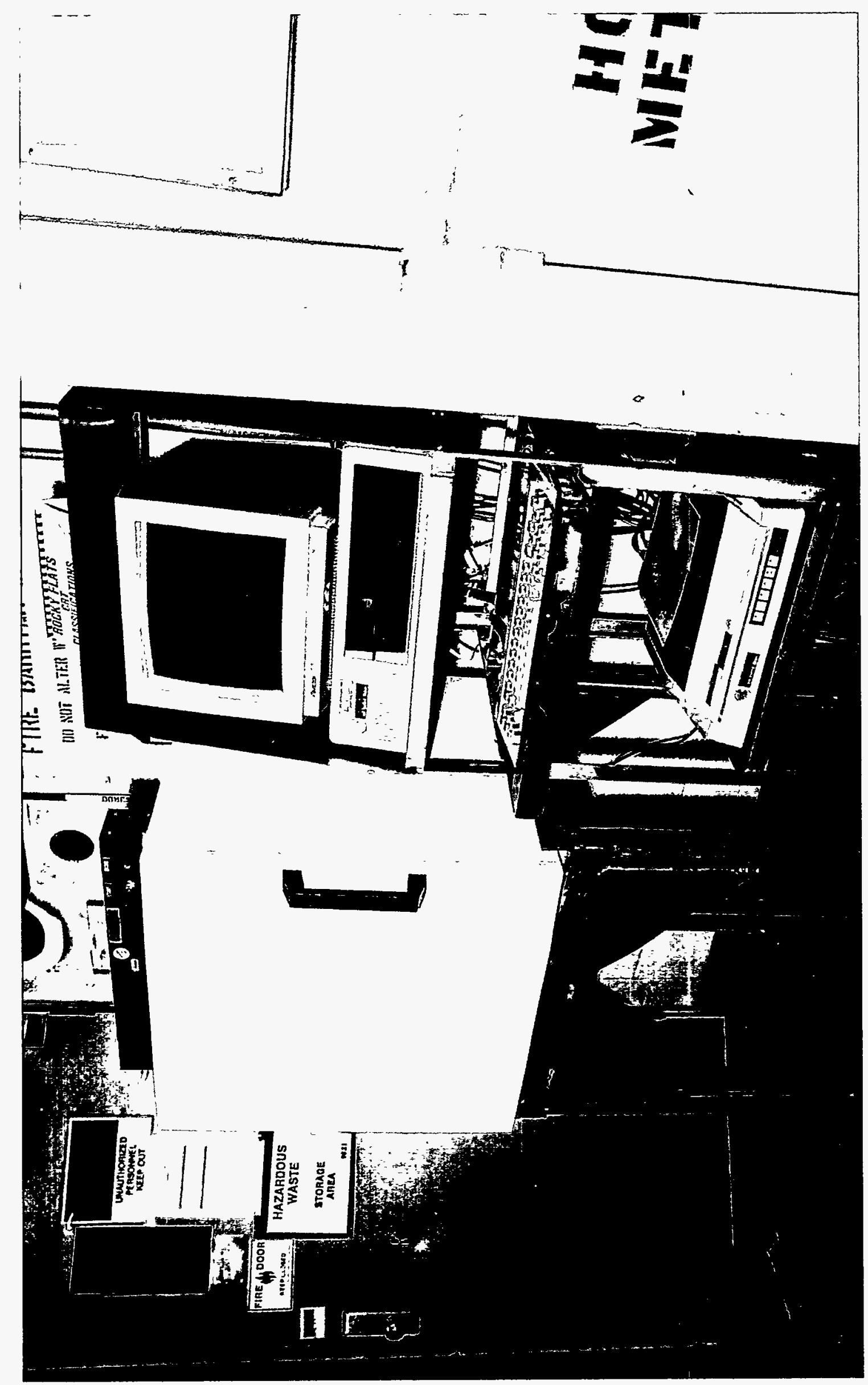

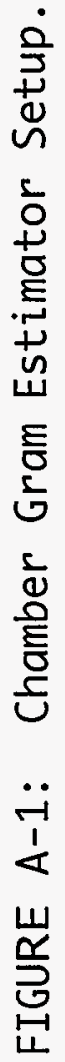




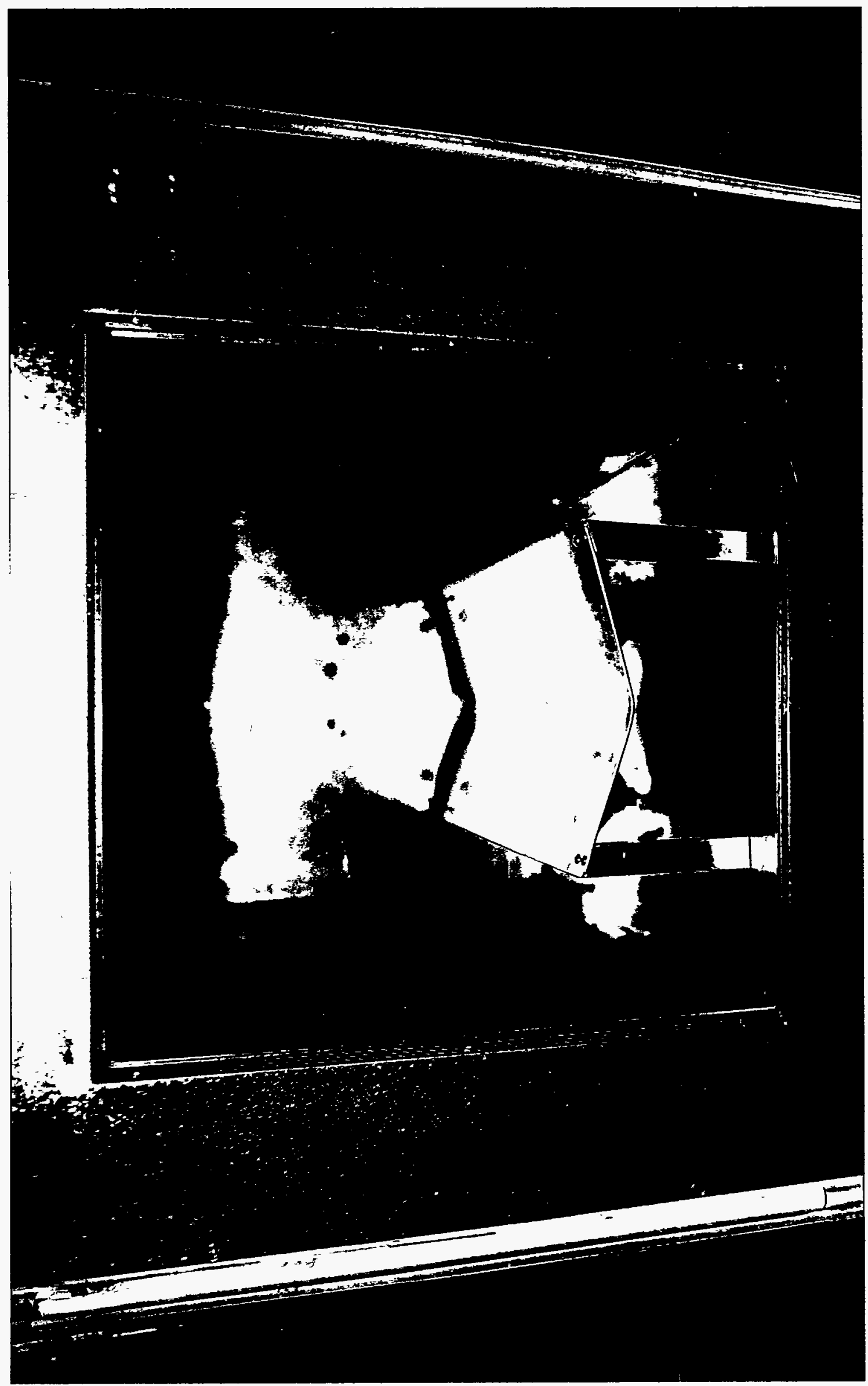

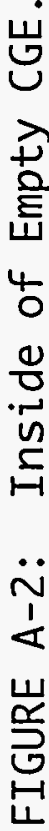




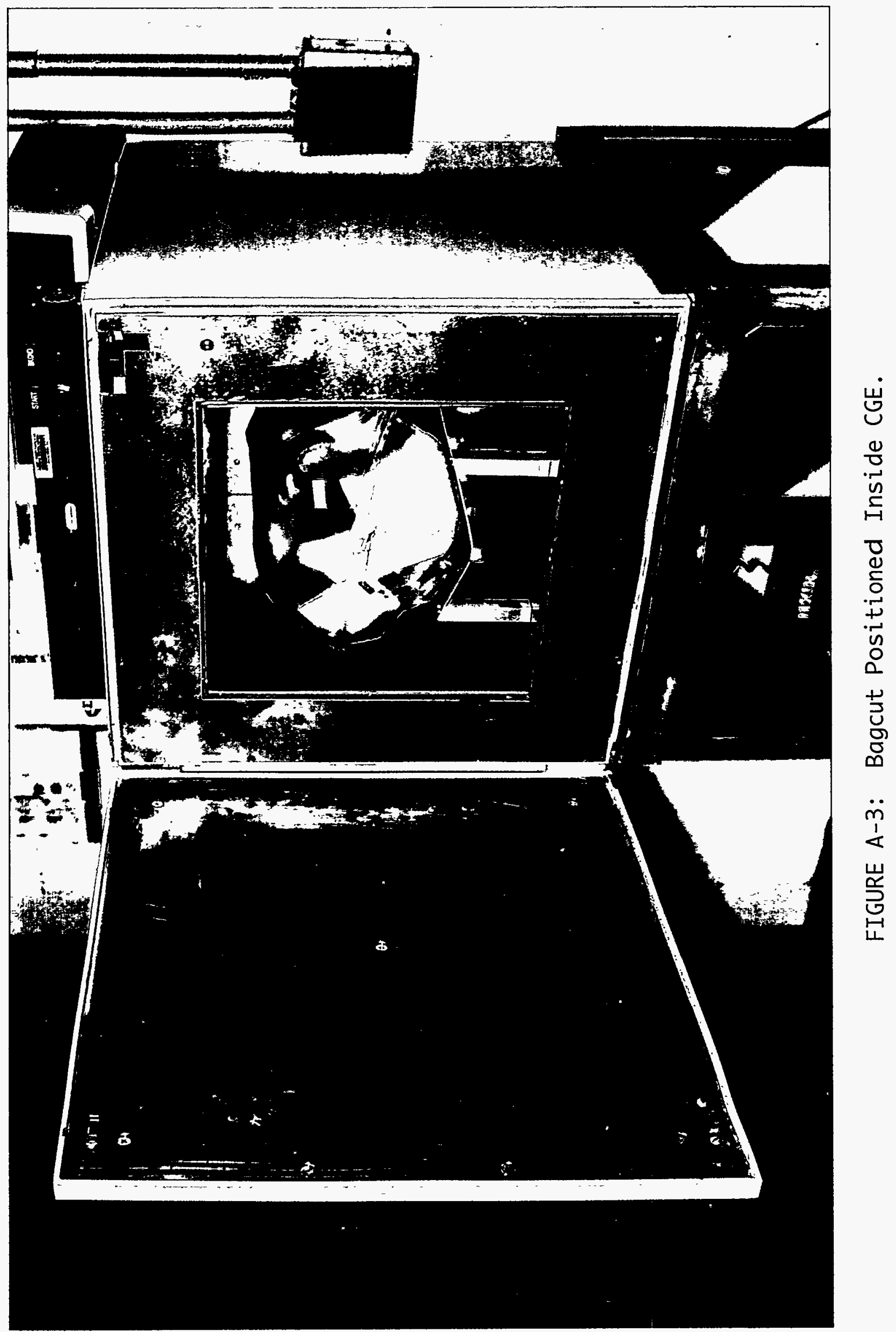




\section{APPENDIX B}

PRESET COUNT AND FIXED REAL-TIME PULSE HEIGHT SPECTRA 


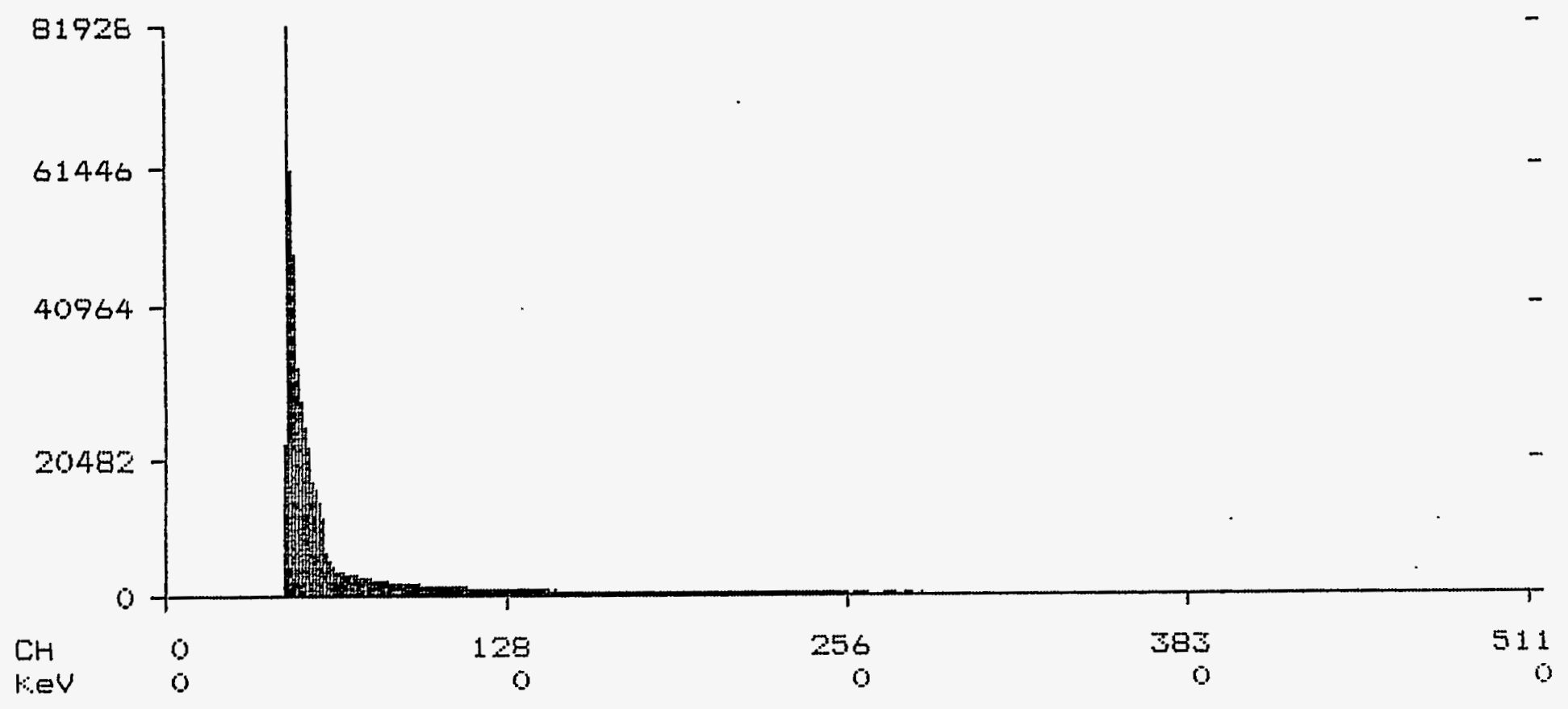

FIGURE B-1a: Preset 400,000 Count Pulse Height Spectra Background. 


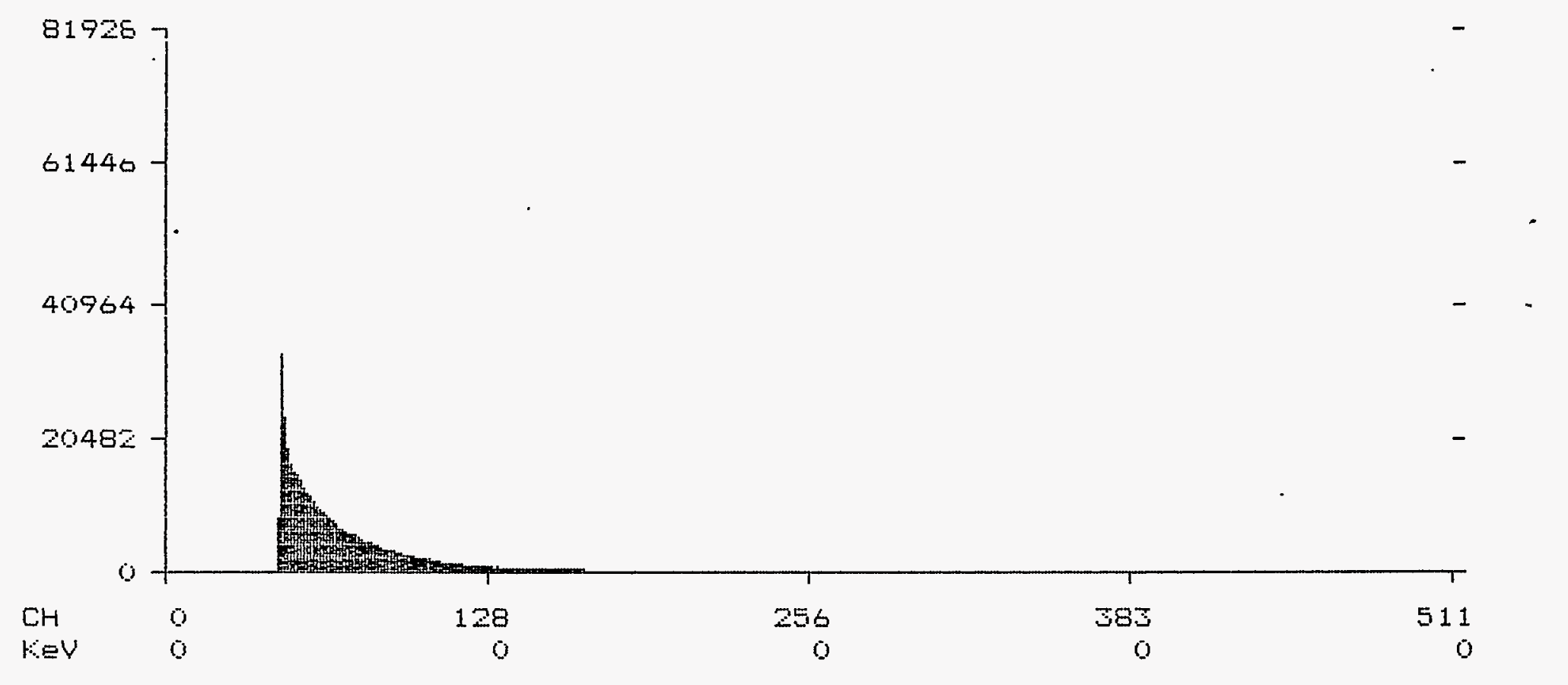

FIGURE B-1b: Preset 400,000 Count Pulse Height Spectra 5 Gram $\mathrm{PuO}_{2}$ Standard Source. 


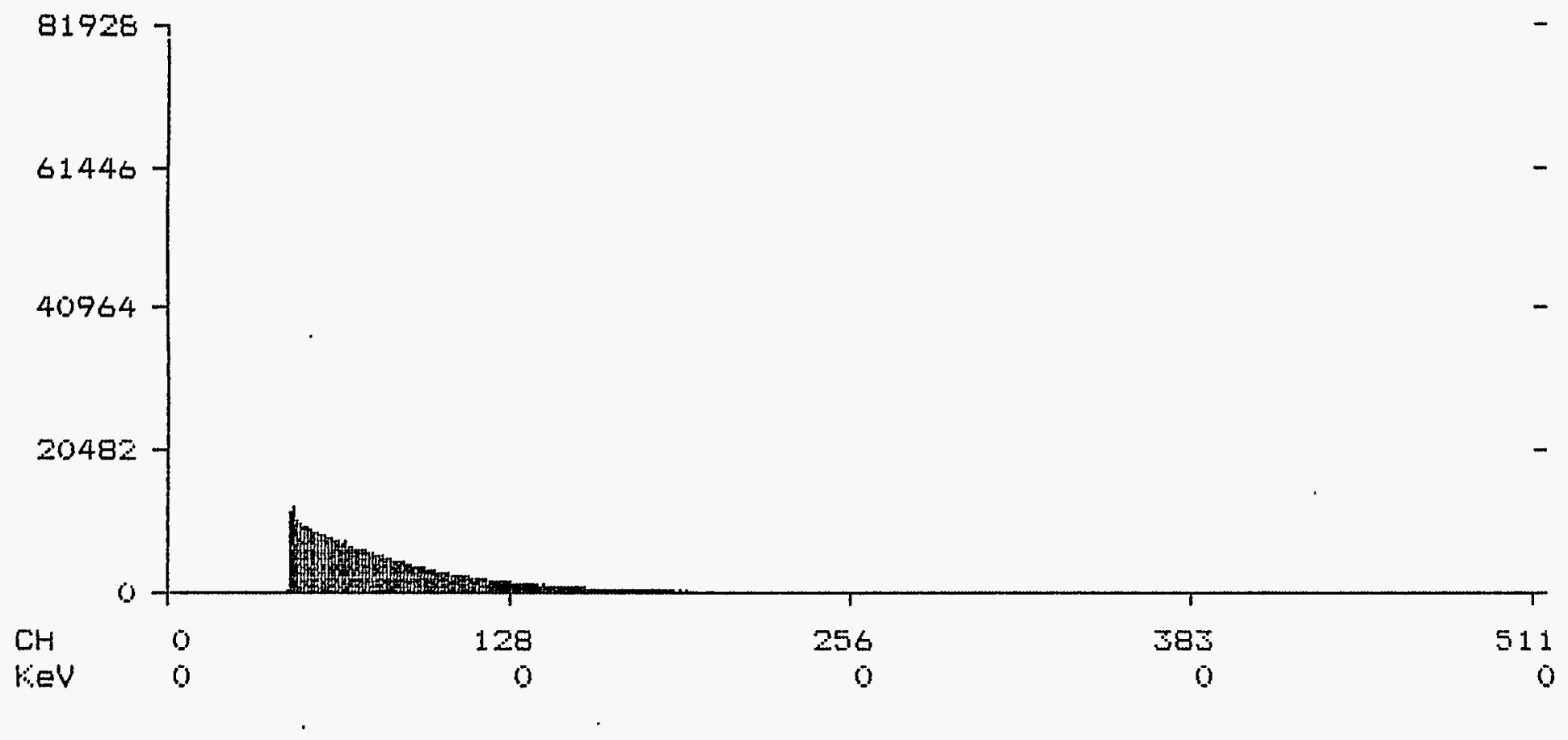

FIGURE B-1C: Preset 400,000 Count Pulse Height Spectra 50 Gram $\mathrm{PuO}_{2}$ Standard Source. 


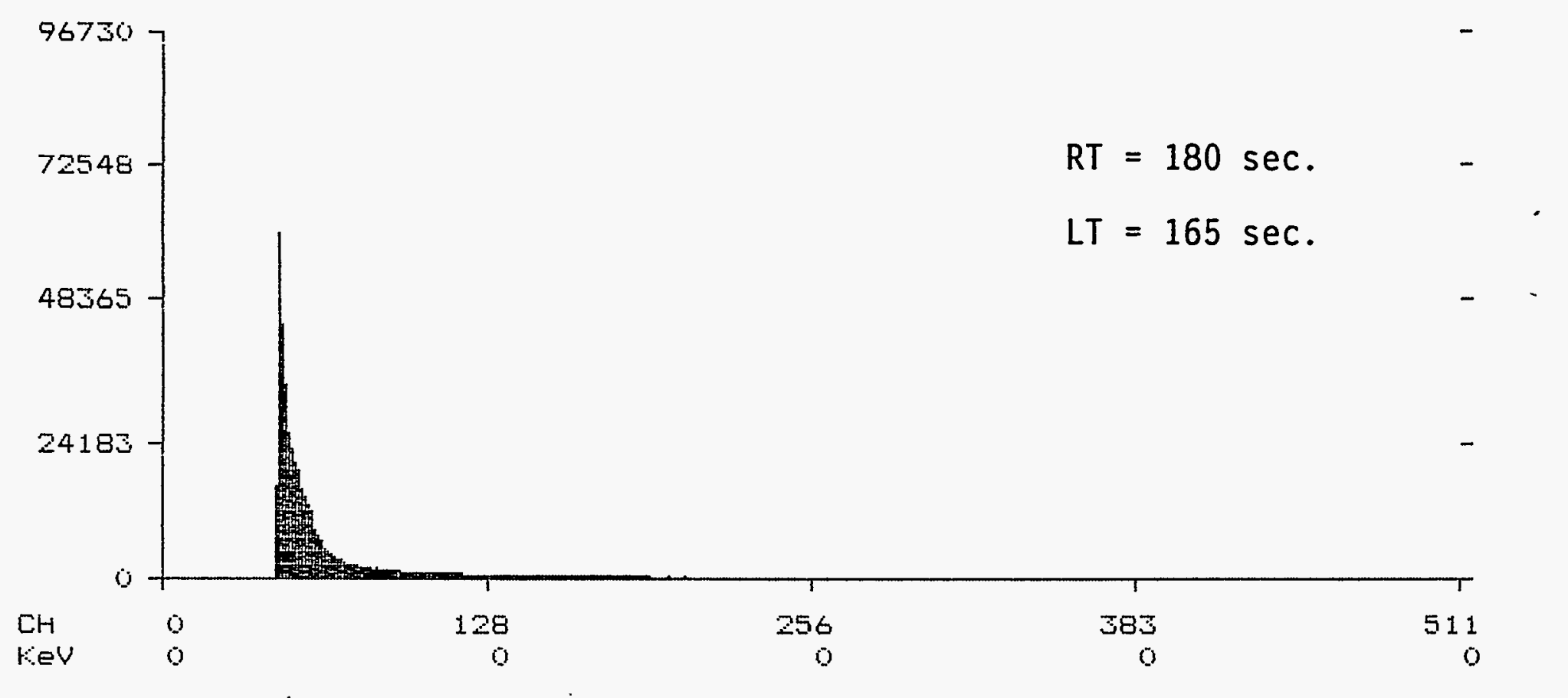

FIGURE B-2d: Fixed Real-Time Pulse Height Spectra 5 Milligram ${ }^{241}$ Am Standard Source. 


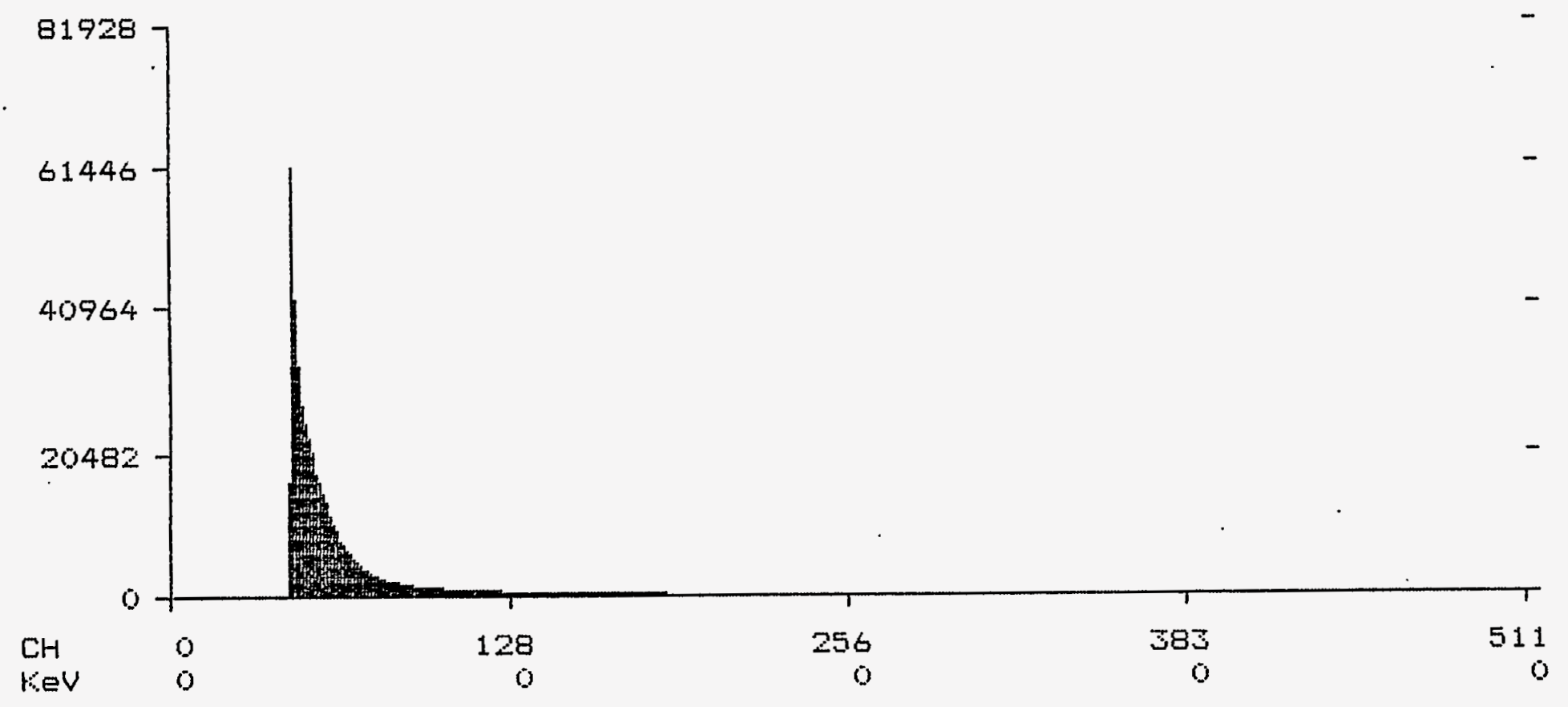

FIGURE B-1e: Preset 400,000 Count Pulse Height Spectra 50 Milligram ${ }^{241} \mathrm{Am}$ Standard Source. 


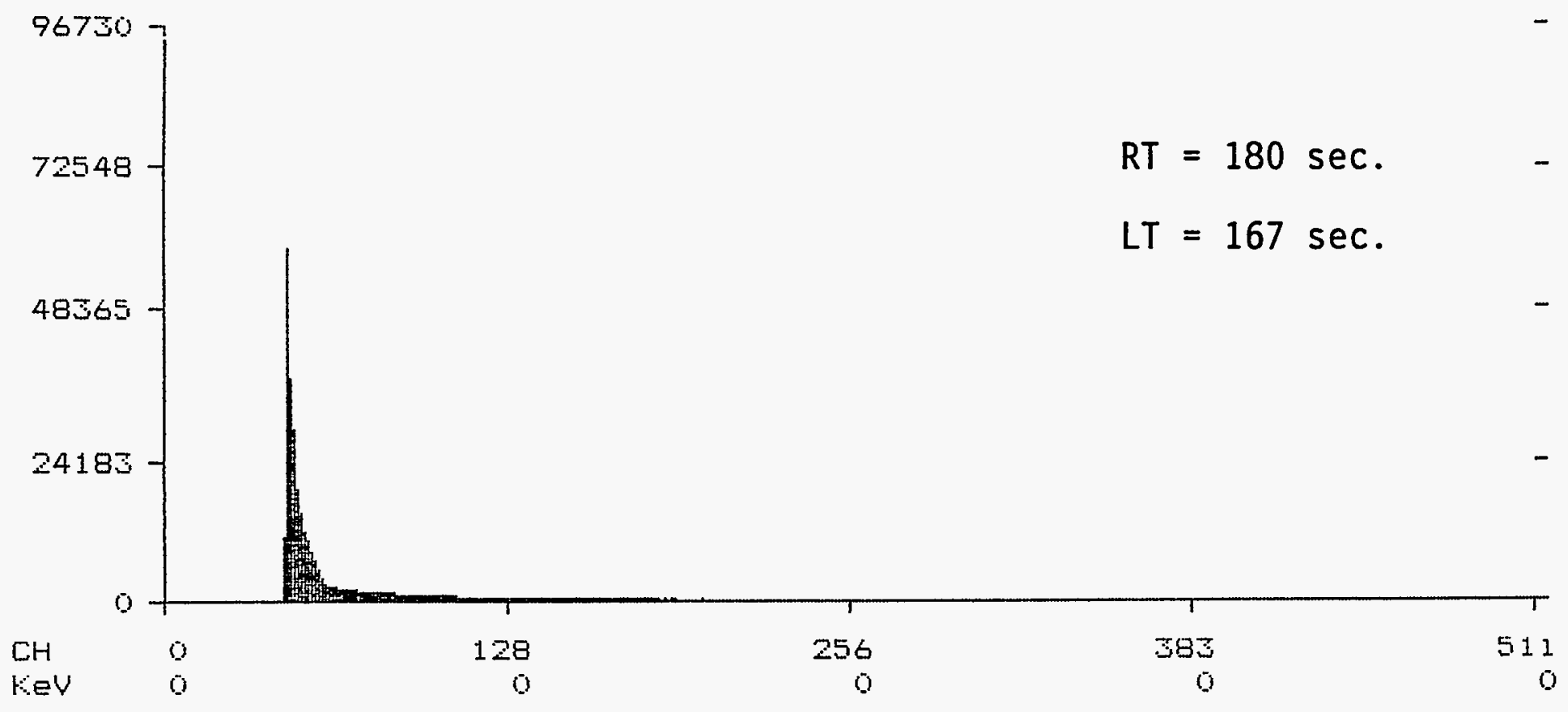

EFGND

FIGURE B-2a: Fixed Real-Time Pulse Height Spectra Background. 


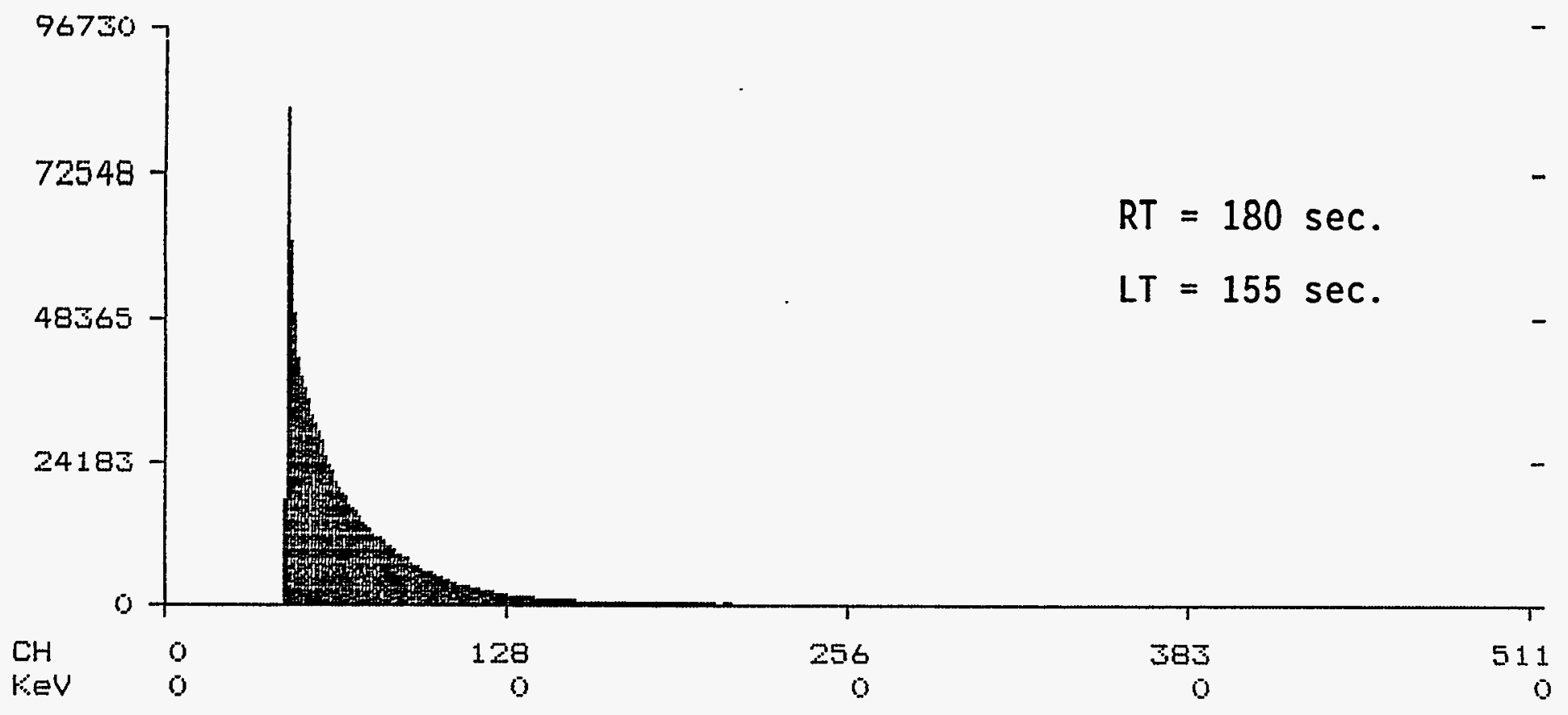

FIGURE B-2b: Fixed Real-Time Pulse Height Spectra 5 Gram $\mathrm{PuO}_{2}$ Stañdard Source. 


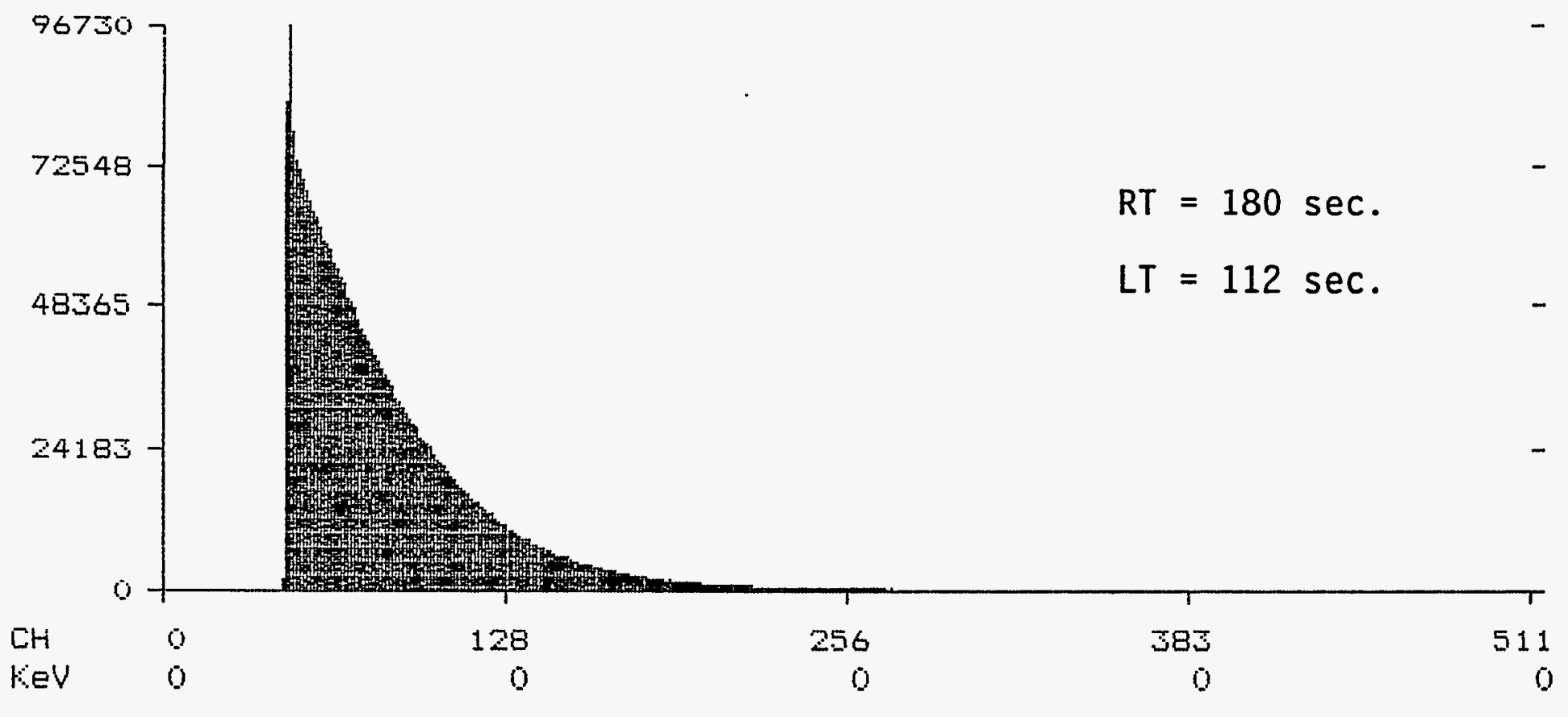

FIGURE B-2c: Fixed Real-Time Pulse Height Spectra 50 Gram $\mathrm{PuO}_{2}$ Standard Source. 


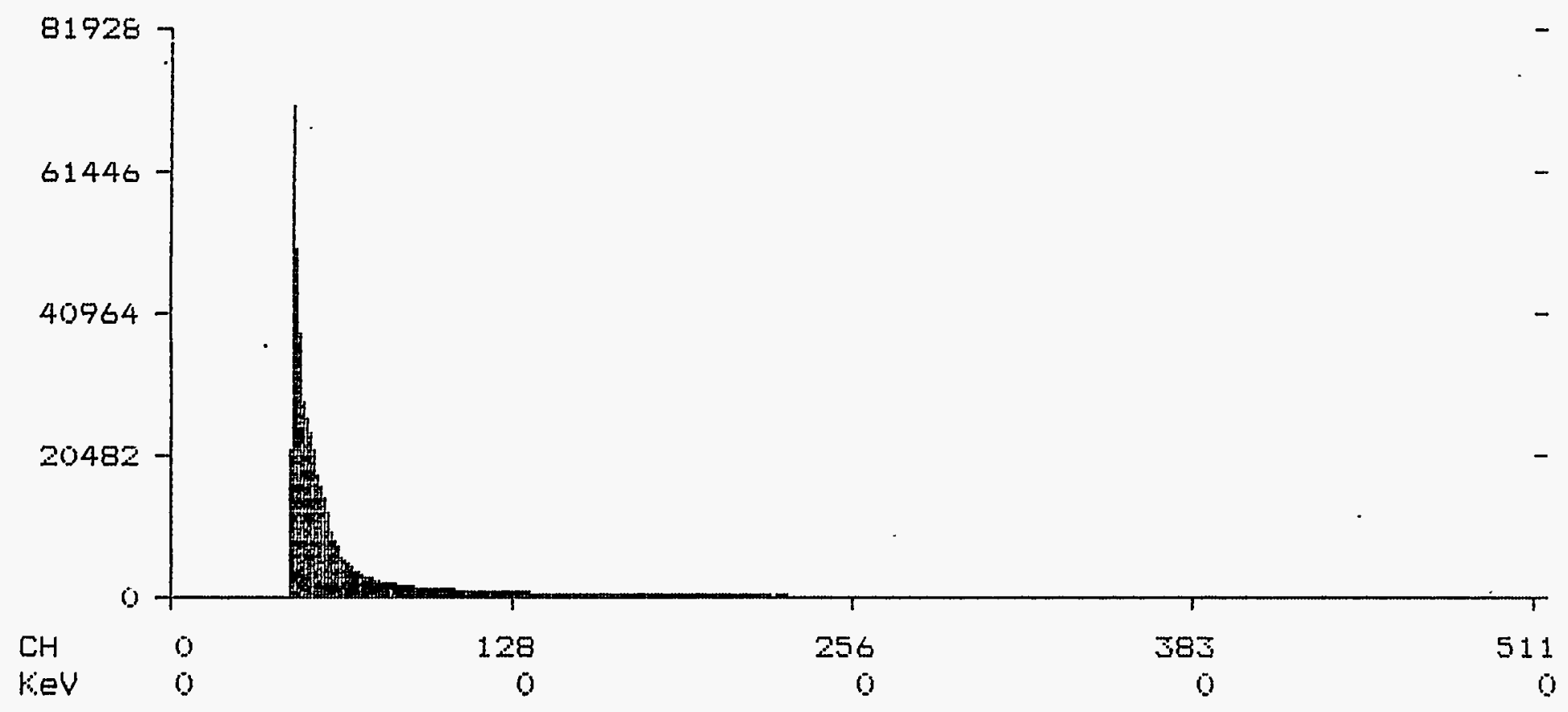

FIGURE B-1d: Preset 400,000 Count Pulse Height Spectra 5 Milligram ${ }^{241} \mathrm{Am}$ Standard Source. 


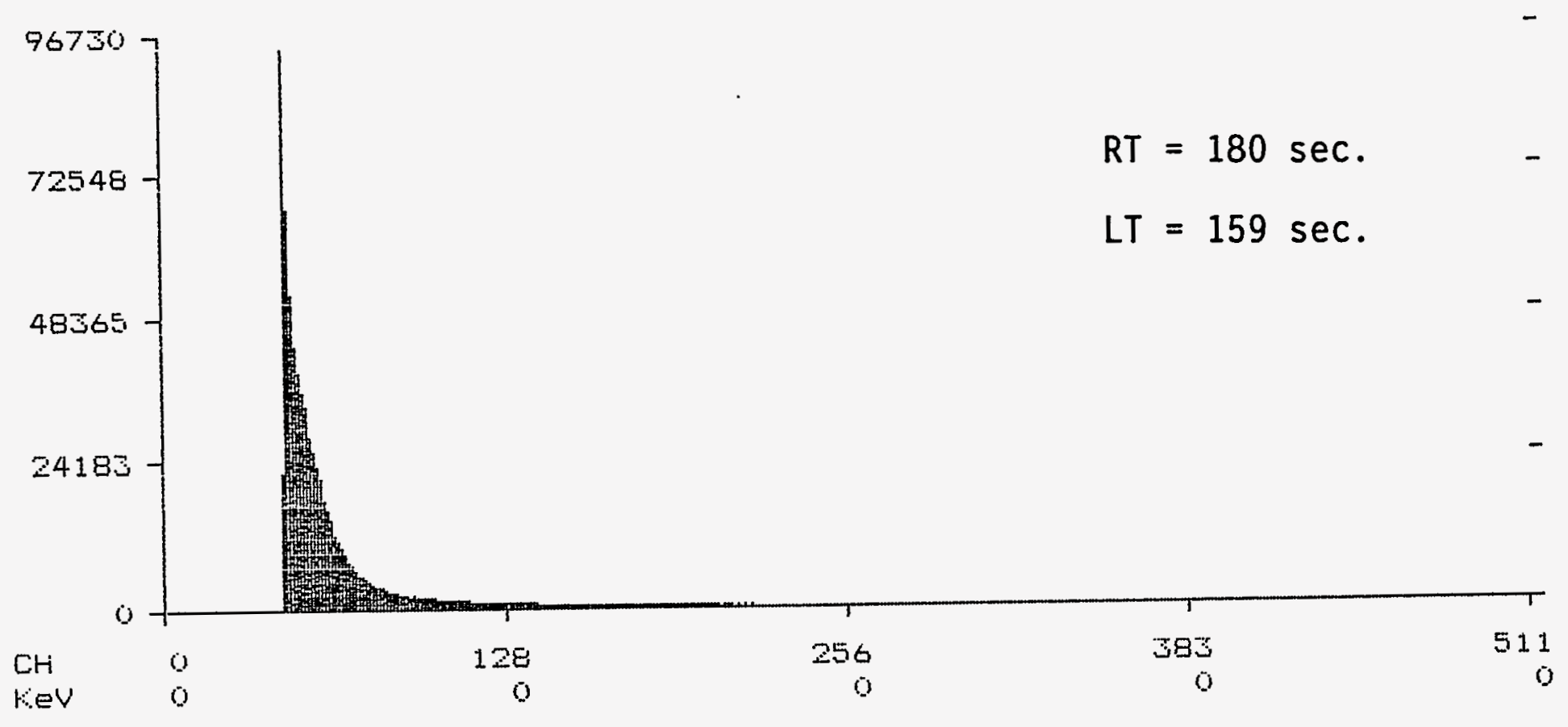

FIGURE B-2e: Fixed Real-Time Pulse Height Spectra 50 Milligram ${ }^{241}$ Am Standard Source. 